\title{
DE LAS COSAS COMUNES A TODOS LOS HOMBRES NOTAS PARA UN DEBATE
}

\section{OF THE COMMONS THINGS TO ALL MEN NOTES FOR A DEBATE}

\section{Rodrigo MígueZ NúNẼz}

\begin{abstract}
RESUMEN: A partir de la crítica a la expansión de la propiedad privada en áreas consideradas esenciales para la existencia y perfeccionamiento de la persona, el presente estudio ofrece reflexiones teóricas en torno al actual debate en la materia de los bienes comunes. Se consignan herramientas histórico-comparativas dirigidas a una relectura del art. 585 del Código Civil y del interés colectivo yacente en la propiedad pública y privada.
\end{abstract}

Palabras clave: Bienes comunes, res communes omnium, revolución científica, propiedad, Código civil chileno.

ABSTRACT: This paper presents a critical overview of the progressive extension of private property in the area of goods considered essential for the existence and development of the person. The study provides historical and comparative tools leads to a reinterpretation of the art. 585 of the Civil Code as well as of the collective interest involved in the public and private property in the light of the current debate on commons theory.

Key words: Commons, res communes omnium, scientific revolution, property, Chilean civil code.

1. El estudioso que emprenda el tratamiento de la propiedad privada deberá ponderar una elemental cuestión, de carácter político-económico, que el instituto propone en todo tiempo y sociedad: su campo de aplicación. En su examen comprenderá que para ciertos bienes la propiedad no puede ser eliminada completamente y que para otros resulta imposible extenderla. Sopesará entonces una serie de factores de diversa naturaleza: de la historia a la filosofía, de la experiencia de su propio país al confronte con otras latitudes, de la naturaleza de los bienes a la función que deben cumplir. Y establecerá, en definitiva, que el núcleo del principal debate que enfrenta a los operadores políticos, económicos y jurídicos gira en torno a la decisión fundamental de considerar ciertos bienes o dentro o fuera del mercado y entonces a establecer un límite entre aquellas cosas que permanecerán en poder del Estado, o de la Nación toda, y las que quedarán entregadas al dominio de los particulares ${ }^{1}$.

En la actualidad la decisión sobre la titularidad de los bienes cobra una especial importancia frente al progresivo deterioro de los recursos naturales, la privatización de los bie-

* Profesor de Derecho civil, Universidad Alberto Hurtado. Doctor en Derecho y Ciencias Sociales, Ecole des hautes études en sciences sociales; Doctor en Derecho Civil, Universidad de Turín. Correo electrónico: rmiguez@uahurtado.cl.

1 Así lo advierte Peñailillo Arévalo (2007) pp. 81-82. En lo que respecta a los conflictos derivados de la tensión público-privado en materia de bienes nacionales de uso público es fundamental: Vergara BlanCo (1997); Vergara Blanco (1999). 
nes públicos y el consecuente debilitamiento de los derechos fundamentales relacionados a ellos. Así, los procesos de privatización impuestos por el progresivo desmantelamiento del Estado social y por el resultado de las recientes políticas neoliberales ponen hoy al centro del debate la privatización de áreas retenidas sensibles por la ciudadanía por concernir bienes esenciales para la existencia y el perfeccionamiento de la personalidad. Todavía, no es blanco de críticas el modelo de la propiedad privada en sí sino las políticas públicas que han consentido la intromisión desfrenada del mercado, y de la consecuente ganancia económica, en dichas áreas. De esta forma, la discusión actual en la materia se reduce a determinar hasta qué punto puede el mercado condicionar la existencia y el acceso a ciertos bienes denominados comunes ${ }^{2}$.

El radio de críticas, se podrá advertir, es amplio. Una errada privatización en la gestión de la energía, del derecho a la educación, a la salud, o del acceso a los más variados bienes y saberes considerados primarios para la realización de la persona, conduce a una crisis de confianza en las instituciones y en la representación ciudadana, imponiendo al observador jurídico una necesaria reflexión conceptual sobre el campo de aplicación de los diversos regímenes de propiedad ${ }^{3}$.

Es en este debate donde -a partir de experiencias que en el Derecho comparado plantean una radical reformulación de la teoría del dominio público- se propone la voz de los bienes comunes como categoría jurídica idónea para garantizar el acceso -y goce- a recursos considerados esenciales para la realización de correlativos derechos constitucionales. El planteamiento, como veremos, es profundo pues precisa una concepción renovada de la relación entre el mundo de las personas y el mundo de las cosas capaz de edificar una alternativa a la gestión pública que deposita el gobierno de los bienes comunes en la lógica propietaria ${ }^{4}$.

2. En su incisivo libro Slide Mountain: Or, the Folly of Owning Nature, el historiador del derecho Theodore Steinberg explora los dilemas de vivir en una cultura donde el medio ambiente, en su totalidad, ha sido transformado en una gran abstracción legal ${ }^{5}$. Ello, argumenta el autor aportando relevante casuística, se ha tornado evidente durante el siglo XX. Así, a medida que el desarrollo tecnológico y científico permitía descubrir nuevas fuentes de valor, el derecho de propiedad ha evolucionado para incorporar los nuevos recursos al

\footnotetext{
2 Rodotà (2011a) p. 240. Como se sabe, la expresión bien varía su contenido según sea el discurso en el cual se inserta y así se advierte que para efectos de este escrito se homologa el término a la voz cosa pues se lee desde una perspectiva estrictamente jurídica, o sea, como cosas tendientes a satisfacer y garantizar derechos y no en el sentido económico, que domina en el Derecho civil patrimonial, y que ve en los bienes parte del activo del titular, valorados exclusivamente por su utilidad y apropiabilidad. Para más detalles, cfr. Pugliatti (1959) p. 169. Debe también precisarse que dicha elección confiere una mayor importancia al sujeto, en su dimensión de homo civicus, que al bien mismo y por consiguiente se posiciona en la tradición de la teoría general del derecho que reserva la palabra bien para referir al perfil objetivo de cualquier interés protegido. Sobre esta y otras acepciones modernas del léxico, cfr. Gambaro (2012) pp. 61 y ss. Entre nosotros véase Peñailillo Arévalo (2007) pp. 14 y ss.; GuZMÁn Brito (1995) pp. 55 y ss.

3 Véase Marella (2011) p. 103.

4 RODOTÀ (2011b) p. 3.

5 STeinberg (1995) p. 10.
} 
mundo de las relaciones de mercado. Luego de dicha evolución -que tiene fecha cierta de inicio: los descubrimientos en todas las áreas realizados por los padres de la revolución científica iniciada en el siglo $\mathrm{XVI}^{6}$ - la tierra, sus productos y toda creación humana, ha sido reducida a un conjunto de cosas objeto de apropiación, es decir, a meros bienes económicos, valorados, como tales, por la utilidad monetaria que prestan al hombre. En este ámbito, debe puntualizarse que la concepción de la propiedad inaugurada por quien es considerado uno de los padres teóricos del individualismo, John Locke, ha jugado un rol fundamental en el establecimiento de la ecuación que separa y coloca al titular del dominio en una relación de superioridad respecto a la cosa, confiriendo al moderno Derecho occidental aquel distintivo carácter antropocéntrico ${ }^{7}$.

Pero fijemos el punto. Los descubrimientos de la ciencia y los cambios en las dinámicas Estado-ciudadano, acelerados con intensidad sin precedente durante el siglo XX, iban siendo abrazados por la teoría de la propiedad ${ }^{8}$. En sede doctrinaria dos esenciales aportes ilustran, desde perspectivas diversas, el mismo fenómeno. En 1964 Charles Reich, profesor de la Facultad de Derecho de la Universidad de Yale, publica en el Yale Law Journal un artículo titulado The New Property. Su objetivo consistía en evidenciar las nuevas situaciones no aún propietarizadas a que daban lugar las concesiones, derechos y permisos otorgados por el Estado. Estas formas de riqueza requerían protección y así, si la tarea primaria del Estado consistía en proteger al individuo, nacía entonces la necesidad de salvaguardar las inéditas formas jurídicas mediante la creación de una nueva propiedad ${ }^{9}$. Con anterioridad, en Italia, el civilista Salvatore Pugliatti titula su intervención en el Tercer Congreso Nacional de Derecho Agrario La proprietà e le proprietà ${ }^{10}$. El escrito, destinado a convertirse en

\footnotetext{
6 Son iluminantes sobre el argumento las obras de Merchant (1980) y Capra (1982). Véanse además notas 56 a 59.

7 Véase Graham (2011) pp. 37-38; Rèmond-Gouilloud (1989) p. 45. El tema es desarrollado con mayor detalle en inédita obra de BuRdon (2013). Sobre el rol de la teoría de LocKE en la formación de la economía de mercado, cfr. Macpherson (1962); Wood (2002); Coyle y Morrow (2004).

8 Debe apuntarse que la sustracción del haber común (o del dominio público) de ciertos bienes, recursos u objetos de creación humana (o del patrimonio cultural de los pueblos) ha generado un intenso debate en torno a la función de la propiedad intelectual en una infinidad de áreas. En una sociedad siempre más vinculada al conocimiento, a la información y a las ideas, la penetración del capitalismo en ámbitos no aún colonizados por la propiedad despierta el interés de filósofos, juristas y antropólogos. David Harvey ha calificado el fenómeno como acumulación por desposesión; James Boyle nos habla del segundo movimiento de cerramiento de los comunes; Michael Hart y Antonio Negri destacan la necesidad -paradójica- del capitalismo actual de expandir la noción de lo común en los ámbitos de la información y del conocimiento para lograr el acceso universal a la tecnología que el mercado ofrece. Cfr. Harvey (2003); Boyle (2003a); Hart y Negri (2009); Benkler (1999); Shiva (1997). Para reflexiones generales sobre estas temáticas, véase DAVIES (2007) pp. 65 ss. Entre nosotros cfr. Schmitz Vaccaro (2009); Ramis (2012). Nótese además que el fenómeno de la expansión de la propiedad intelectual, a diferencia de la privatización de la tierra, recurso ya escaso al momento de estallar el movimiento del cerramiento de las heredades del siglo XVII, tiene por objeto un bien o una serie de bienes que, en la generalidad de los casos, no son en sí escasos y de los cuales, mediante la introducción de la lógica propietaria, se tiende a crear una situación de escasez. Véase Rodotà (2007) p. 362.

9 Cfr. Reich (1964); Reich (1990). Sobre el valor y extensión de la obra de Reich en la moderna teoría de la propiedad, véase RoDOTÀ (1990) pp. 47 y ss.

10 Pugliatti (1954 [1952]).
} 
una referencia obligada para toda una generación de estudiosos ${ }^{11}$, marca un profundo quiebre en la teoría del Derecho de propiedad continental, pues hay allí, y por vez primera, una reflexión propietaria que no recae sobre el sujeto, sino sobre la cosa misma. La cosa en Pugliatti requería observarse en perspectiva detallada, con características específicas y diversas, de las cuales nacían -y se requerían- diversas y peculiares construcciones jurídicas. De esta forma, de los diversos tipos de bienes se arribaba a la edificación de diversas propiedades, con estructuras propias y particulares, las cuales relativizaban el modelo de la propiedad monista del Código Civil ${ }^{12}$.

La evolución jurídica chilena sigue, por cierto, el itinerario esbozado. Las nuevas propiedades, derivadas de nuevas categorías de bienes, creaciones y situaciones, evidenciaban también en nuestro Derecho la limitación estructural de la propiedad del Código, dando paso al gradual desprendimiento del modelo dominical por él previsto. Así, en cuadro sucinto, a la propiedad intelectual (1925) e industrial (1931) se suma la propiedad horizontal (1937), la propiedad austral (1927), sin olvidar la indígena, creada mediante la dación de títulos de merced (1884-1929). Además, nuevas formas de uso de la tierra planteaba la legislación agraria que, a punta de reformas más o menos radicales, se impone como constante durante la segunda mitad del siglo XX. A lo dicho se debe añadir la comerciabilidad, si bien limitada, que a ciertos bienes nacionales confieren leyes especiales, como la Ley sobre Adquisición, Administración y Disposición de Bienes Nacionales (1979), el Código de Aguas (1981) y la Ley Orgánica Constitucional sobre Concesiones Mineras (1982).

Por otro lado, es sabido que la evolución legislativa chilena ha profundizado -y con certeza irrefutable a partir del texto constitucional de 1980- la llamada bipolaridad publicatiolapropriatio en materia de bienes ${ }^{13}$ confiando un restringido ámbito a las cosas inapropiables, categoría ancestral que, como veremos en breve, nuestro ordenamiento no olvida a partir de una máxima dispuesta por el Código Civil. Así, en nuestro derecho los bienes o son públicos (apropiables en su naturaleza, no comerciables por su destino, salvo excepciones) o son privados (apropiables/comerciables). Pero ello no es todo, pues debe también advertirse que el creciente fenómeno de la propietarización de algunos ámbitos del dominio público nacional -consentido por un sistema que no reconoce derechos administrativos específicos a los titulares de derechos sobre bienes públicos- transporta y asimila bienes de su patrimonio a la esfera de la propiedad privada ${ }^{14}$. Notorio es en la materia el silogismo de los arts. 565, 576, 583 del Código Civil, que complementado por los arts. 19 No 24 inc. $1^{\circ}$ y 20 de la Constitución Política, configura un sistema de protección de garantías constitucionales arraigado en el uso -y abuso- del recurso de protección sobre la base del parámetro propietario ${ }^{15}$.

Resulta por tanto forzoso dar razón a Kevin Gray cuando sostiene que en la actualidad los jueces y legisladores parecen obsesionados con la necesidad de formular las percep-

\footnotetext{
11 Como lo evidencia recientemente Carapezza Figlia (2012a) pp. 1062-1063.

12 Véase, Grossi (1988) p. 361. Véase, además, Cordero (2008) pp. 513-515.

13 Vergara Blanco (2001); Vergara Blanco (2002).

14 Vergara Blanco (1999); Zúñiga Urbina (2005).

15 Vergara Blanco (1991) p. 288.; Guzmán Brito (1995) p. 236; Castellón y Rebolledo (1999) pp. 99 y ss.
} 
ciones humanas del mundo exterior en los intangibles términos de la apropiación individual y de la propiedad privada. Ello, a su vez, es solo la huella de un fenómeno todavía más general, ya que nuestras vidas, agrega el estudioso, "se encuentran dominadas, en todos sus aspectos, por un sentido intuitivo de propiedad y de pertenencia"16.

Ahora bien, interesa seguir precisando este punto porque es indiscutible que la noción de la propiedad, bien anclada en el subconsciente colectivo, comprende hoy el entero imaginario de relación con los bienes, abrazando, con los problemas y limitaciones que derivan de su estructura, un sinnúmero de situaciones para las cuales no parece idónea.

La insuficiencia conceptual de la propiedad se observa no solo en la problemática derivada de su ensanche progresivo en el ámbito del dominio público, ni en el reforzamiento de la subjetividad o de lo perteneciente al sujeto; el fenómeno debe ser también analizado a la luz de las nuevas palabras que recorren el mundo actual y que dan fe de la creciente dimensión de lo común: software libre, no copyright, acceso libre al agua, a la alimentación, a los recursos naturales, a las medicinas, a la salud, a la educación, a Internet, a la cultura, son expresiones que asumen la vestidura de derechos fundamentales del ser humano ${ }^{17}$; de ahí su eminente vocación publicista y su sensibilidad respecto a la permeabilidad de propiedad privada.

En realidad, dista mucho de ser convincente el planteamiento que entrega ciegamente la reglamentación de dichas áreas a lógicas propietarias puesto que la tesis ignora una elemental cuestión: el derecho de propiedad posee la limitación intrínseca de no comprender la complejidad de la relación entre el hombre y las $\operatorname{cosas}^{18}$. Pero hay aún más: si se acepta -como nosotros lo hacemos- la limitación intrínseca del instituto, se admitirá que la generalización de la propiedad privada se reserva solo para aquellas situaciones donde ya existe un mercado generalizado, por lo que en ausencia de este último, la introducción de la propiedad no sería solo ineficaz, sino que además peligrosa ${ }^{19}$. Pues bien, al vacío no saciable por la propiedad responde hoy la categoría de los bienes comunes; bienes que exigen, como indica Stefano Rodotà, una diversa forma de racionalidad, capaz de encarnar los cambiamientos profundos que estamos viviendo ${ }^{20}$.

Se va imponiendo una evidente consideración que conviene ahora precisar: la noción de los bienes comunes requiere una reflexión ajena al domino. Es por tal motivo que atrae hoy interés el interrogativo radical propuesto por el jurista estadounidense James Boyle:

\footnotetext{
16 Véase Gray (1994) p. 158. Pero no se piense que se trata de una apreciación nueva. Famosa es la frase de Blackstone: "There is nothing which so generally strikes the imagination, and engages the affections of mankind, as the right of property". Blackstone (1893 [1765-1766]) p. 2. Debe también notarse que entre nosotros Cordero Quinzacara ha caracterizado el estado actual de la dogmática en torno a la garantía del derecho de propiedad en Chile con expresión de subjetivismo, esto es, "un acentuado predominio de lo subjetivo o de lo perteneciente o relativo al sujeto (en este caso el titular del derecho) considerado en oposición al mundo exterior”. Cordero QuinZacara (2006) p. 127.

17 Véase Rodotà (2012b) p. 111.

18 Para profundizaciones sobre la crítica al concepto de propiedad occidental, véase MíguEz Núñuz (2013) pp. 11 y ss.; Míguez NúNEz (2010).

19 Véase Le Roy (2011) pp. 24 y 257 ss.

20 Rodotà (2012a) p. 312.
} 
The Opposite of Property? ${ }^{21}$. Como se advierte, el tema no es el modelo propietario, sino una gestión diversa de los bienes que el autor luego individua, un control que no responde al paradigma del individualismo ni del exclusivismo. Interesa la formulación de Boyle pues nos lleva al centro del tema aquí planteado: la reflexión sobre los bienes comunes no es dirigida al estudio de modelos alternativos de propiedad sino que a lo opuesto a ella. No es la apropiación ni tampoco titularidad del bien el objeto de estudio; lo que se propone es más bien el análisis de la función y gestión de ciertos bienes de vocación colectiva en modo tal de garantizar su acceso y uso ecuánime a todos los ciudadanos interesados.

La tendencia que se va delineando ha traído importantes consecuencias en el plano legislativo. Piénsese en la labor realizada por las Naciones Unidas, que desde el 2002, y con éxito manifiesto en el 2010, introduce una nueva concepción jurídica respecto el agua, rehusando su carácter de bien económico y reconociendo en ella un derecho humano necesario para el perfeccionamiento de la vida y el ejercicio de otros derechos fundamentales ${ }^{22}$; piénsese en el reconocimiento del acceso a Internet, como derecho imprescindible para garantizar el acceso igualitario al conocimiento, así admitido en países como Perú, Estonia, Grecia, Ecuador, Finlandia, entre otros, y promovido en el seno de la Unión Europea y de las Naciones Unidas ${ }^{23}$; piénsese en el nuevo constitucionalismo latinoamericano, que posiciona siempre con mayor nitidez y extensión una gama de recursos naturales y de bienes culturales en la esfera de la inalienabilidad absoluta ${ }^{24}$. Como se puede observar, estas experiencias testimonian la apertura del panorama legislativo hacia una lógica inclusiva en el uso y gestión de los bienes considerados esenciales para el ser humano, permitiendo una perfecta identificación entre bienes primarios y derechos fundamentales.

Por su parte, es también necesario destacar que la insuficiencia de la disciplina del dominio público del Código Civil y el flujo asistemático de leyes especiales en el sector, han determinado el emprendimiento de sendas reformas en España (2003) 25 y Francia $(2006)^{26}$. En Italia el proyecto de reforma de los bienes públicos, depositado en el Parla-

\footnotetext{
21 Boyle (2003b). Destaca hoy Rodotà (2012b) pp. 105 y ss. la importancia de la reflexión de Boyle en la teoría de los bienes comunes.

22 Me refiero al Comentario General No 15 (GC15) sobre el derecho al agua (interpretación legal oficial publicada en 2002 por el Comité de Derechos Económicos, Sociales y Culturales) y a la Resolución de las Naciones Unidas que reconoce el derecho humano al agua y al saneamiento A/RES/64/292, 28 de julio de 2010. Han influido en el contexto del Derecho internacional los innovadores reconocimientos constitucionales respecto a la condición jurídica de la naturaleza y al acceso a sus recursos, cuales derechos fundamentales, realizados por los textos de Ecuador (2008) y Bolivia (2009). Para un primer acercamiento a la experiencia ecuatoriana véase GuDYNAS (2009). Interesantes son, además, los lineamientos generales sobre las consecuencias de estos reconocimientos en tema de derechos de -y a- la naturaleza ofrecidos por ZAFFARONI (2012) pp. 51 y ss.

23 Fenómeno últimamente abordado por ZicCARdi (2013) pp. 125 y ss.

24 Véanse arts. 1, 12, 16, 17, 18, 74 de la Constitución Política del Ecuador; arts. 99, 359, 374 de la Constitución Política de Bolivia. Muy relevante es también la modificación, en materia de derecho al agua, introducida en el 2004 al texto constitucional uruguayo de 1967, cuyo art. 47 hoy reza: "El agua es un recurso natural esencial para la vida. El acceso al agua potable y el acceso al saneamiento, constituyen derechos humanos fundamentales".

25 Ley sobre Patrimonio de las Administraciones Públicas No 33/2003 de 3 noviembre de 2003.

26 Ordonnance No 2006-460 relative à la partie législative du code général de la propriété des personés publiques de 21 abril de 2006. La ordenanza ha sustituido al Code du domaine de l'Etat de 1958, introduciendo además importantes modificaciones a la materia demanial del Código Civil.
} 
mento el año 2008, reedifica el entero lenguaje demanial, confiriendo expreso espacio a la categoría de los bienes comunes. Debe tenerse en cuenta en modo muy particular esta propuesta porque en sus trabajos preparatorios los artífices del proyecto se han servido de una noción propia del Derecho romano, las res communes omnium ${ }^{27}$, conduciendo a una reflexión que trasciende las fuentes vigentes y que precisa del miramiento historiográfico para cotejar las demandas actuales con el acervo jurídico que hemos heredado.

3. En el Derecho romano por res communes omnium se entendían aquellas cosas no pertenecientes a particulares ni a una colectividad política, sino que dejadas al goce de todos los hombres. Se acostumbra a adscribir la formulación de la categoría a Elio Marciano, jurista del siglo III d. C. quien las incluyó en el libro tercero de sus Instituciones (D. 1.8.2.1 $)^{28}$. Marciano, recordado por su educación humanista y por ser el más proclive de los jurisconsultos clásicos a las alusiones literarias y filosóficas, iniciaba el tratamiento de las cosas elaborando una distinción que no correspondía a la summa rerum divisio de Gayo. Su clasificación añadía las res communes omnium, mencionando dentro de ellas -aunque no se sabe si a título taxativo o demostrativo- el aire, las aguas corrientes, el mar y el litoral de este. Tales cosas, se dijo, eran por Derecho natural destinadas al uso común de los hombres y su extrapatrimonialidad derivaba del hecho de ser comunes a todos. El concepto de res communes fue luego acogido como elemento basilar en las Instituciones de Justiniano (Inst. 2.1.1) donde aparece diferenciado de las res publicae populi romani, de las res universitatis ${ }^{29}$ y de las res nullius.

Puede afirmarse que los bienes comunes existieron en Roma para garantizar a los ciudadanos, en modo directo, el acceso y uso de ciertos recursos básicos, los cuales no podían ser sustraídos por el Estado para fines de la colectividad. Por consiguiente, se trató de cosas que la comunidad de los hombres usaba y gozaba fuera de la esfera de acción del Estado, en modo abierto e ilimitado, diferenciándose de la categoría de las res publicae ${ }^{30}$. Las res communes fueron además categoría diversa de las res nullius, puesto que cada uno usaba la cosa como propia y la utilidad que se extraía de tal uso era considerada individual, transformándose en un real Derecho subjetivo, protegido por el Estado como tal. Lo anterior no significaba conferir un derecho de apropiación exclusiva en términos de valor de cambio, se trató más bien de una garantía conferida a cada ciudadano en términos de uso, reflejo de

\footnotetext{
27 LuCarelli (2010) p. 90; LuCARelli (2007) p. 91.

28 No obstante, se ha sostenido que ella sería una categoría aun más antigua y que la doctrina romana moderna no pudo sistematizarla ya que aparecía confundida con la expresión res nullius. Sobre el punto, es iluminante una observación de Bonfante quien enseña que Gayo entendió las res nullius "como de ninguno en particular porque pertenecían a todos”. Cfr. Bonfante (1966) p. 82. Asimismo, las res communes (referidas al mar y su litoral) fueron conocidas por otros juristas clásicos como Neracio, Celso y Ulpiano, por lo que siguiendo la opinión de Grosso puede afirmarse que la categoría enunciada por Marciano obedece más bien al fruto de un largo proceso de refinamiento conceptual. Grosso (1941) p. 98. Véase, además, Maddalena (2011) pp. 2615-2618.

29 Esto es, las cosas pertenecientes a las varias ciudades, diversas de la capital y que según un uso impropio, pero radicado, son también llamadas públicas. Cfr. Voci (1998) p. 308.

30 Conviene advertir que el fundamento de las res communes omnium y su diferenciación respecto a las res publicae es materia de constante debate en la doctrina romanista contemporánea. Para todas la voces véase: ZoZ (1999) pp. 35 y ss., 59 y ss.; Fiorentini (2010).
} 
la facultad presente en toda sociedad de disponer al propio fin de la cosa común -e incluso de apropiársela en cantidad inocua-, limitada solo por el uso igualitario y concurrente de los demás componentes del grupo ${ }^{31}$. De esta forma, reconociéndose que determinadas cosas eran comunes a todos, el Estado no pudo tener sobre ellas derecho de plena y absoluta disponibilidad.

Como consecuencia de la caída del Imperio romano se generó un declive sus estructuras dando paso a una proliferación de organizaciones políticas locales y al retorno de formas de economía de subsistencia. Jurídicamente, la nueva etapa no podía ser comprendida con el prisma del Derecho romano pues, es sabido, este se fundaba en la lex -muy florida desde tiempos de la República- y en un creciente poder normativo arrogado al -y por elEmperador ${ }^{32}$. Así, donde el Derecho romano ofrecía creación y ordenación centralizada de normas, el medioevo prescindía del monopolio jurídico conferido al poder centralizado para dar lugar a un derecho voz de la sociedad, de los innumerables grupos sociales, cada uno de los cuales encarnaba un ordenamiento jurídico diverso ${ }^{33}$. En el nuevo contexto el derecho no podía concebirse de otro modo, ya que el medioevo ofrece al observador una crisis de poder, un vacío derivado de la incapacidad de la organización política de establecer un ordenamiento omnicomprensivo. Pues bien, es en medio de esta laguna donde el Derecho -sobre todo aquel que hoy llamamos privado- se multiplicará a partir de la cotidianidad local ofreciendo aquella inagotable diversidad, carente de vocación universalista y absolutista, propia de la Edad Media.

En el campo de la teoría de la apropiación, es preciso notar una ulterior consideración que conduce a otro esencial contraste. Se sabe que el Derecho romano resolvía el cuadro de los derechos reales en un esquema centrado en la pertenencia, en la titularidad de los bienes. Como indica Grossi, se trataba de un esquema unitario pues se construía desde el punto de vista del sujeto, entidad no divisible; potestativo, porque la relación hombrebien era pensada en términos de poder sobre las cosas; y absolutista, porque la apropiación de un bien era vista como la expresión de la libertad del sujeto ${ }^{34}$. Todo, en cambio, fue diverso durante el medioevo jurídico. Frente al antropocentrismo del Derecho romano el Derecho medioeval impuso como elemento central la cosa, sumergiendo al individuo, cual ente abstracto y secundario, en la dimensión del grupo (la parroquia, la asociación política, la corporación profesional, la fraternidad, etc. ${ }^{35}$. Fue así que en una realidad compleja, donde el individuo aislado tendría por destino el exilio o la muerte, que el grupo, la colectividad, la adscripción a una asociación normada y dirigida a un objetivo común, sería deseada en cuanto necesaria para asegurar la propia subsistencia ${ }^{36}$.

Todo esto explica porque el individualismo fue un fenómeno extraño a la mentalidad medieval en las diversas dimensiones del saber y del diario vivir y porque la comu-

\footnotetext{
31 Véase Voci (1998) p. 313.

32 Sobre dichos carácteres cfr. SCHIAVOne (2005) pp. 74 y ss.

33 Grossi (2006) p. 48.

34 Grossi (2006) p. 238.

35 Grossi (2006) pp. 72-74.

36 Véase Treggiari (2012) p. 222.
} 
nidad, en todas sus manifestaciones, fue la verdadera protagonista del ideario teológico, político y jurídico de dicha época. La comunidad, en definitiva, se estatuye como una célula irreductible en una sociedad que no cree en el individualismo, que se edifica en base al plural, en base al colectivo en todas sus manifestaciones ${ }^{37}$.

A la vista de lo dicho se comprende que solo en la unidad organizada (civitates, castra, burgi, villae, colegios eclesiásticos, profesionales, etc.) el individuo pudo obtener el provecho de uso y de ejercicio de los bienes y de los recursos naturales, cuyo control fue conferido a la comunidad en la forma de la iurisdictio ${ }^{38}$. Es esta, la Gemeinschaft germánica, explica Emanuele Conte, el sujeto típico y prevalente del mundo medieval y es a ella, en sus diversas formas (familiar extendida, comunidad de aldeas, corporación), a quien se entregó, mediante procedimientos de naturaleza publicista, el gobierno de los bienes comunes ${ }^{39}$.

Todavía, no se niega que el esquema del dominiun del Corpus iuris haya impregnado de romanismo la sistematización de los derechos reales del medioevo, pero es de apreciar que el dominio directo y útil del que hablan los glosadores, si bien nutrido de la forma romana, se colma de categorías de contenido medieval. De este modo, en el dominio útil, que permitió diversos usos y facultades subjetivas sobre un mismo bien (pastoreo, cultivación, recolección de leña, etc.), es posible entrever formas de colectividad locales: la Gewere alemana, las saisines y tenures francesas e inglesas, la vestidura de la experiencia feudal italiana y el aprovechamiento de los baldíos españoles dan fe de ello ${ }^{40}$.

Desde la perspectiva de las relaciones humanas debe además precisarse que las formas de aprovechamiento y uso colectivo de la tierra prevalecieron en un mundo donde predominaba la noción de estatus sobre la del contrato. El estatus envolvía deberes respecto al grupo familiar o profesional y una solidaridad continua entre los componentes del grupo social. Dicha constatación confirió al Derecho una eminente vocación personalista, esto es, el distintivo de un Derecho específico y diferenciado que el individuo llevaba con sí según fuere el grupo de pertenencia ${ }^{41}$. Así, la vida en los campos se organizaba en torno a estas formas sociales que permitían el establecimiento de una continua cooperación mediante hechos cotidianos, carentes de validez formal, pero ricos en efectividad, dando lugar a un derecho espontáneo, fundido y confundido con la realidad.

Se podrá ya intuir que en este complejo mosaico corporativo la categoría de los bienes comunes fue esencial para la existencia humana y su desarrollo. El bosque, otorgaba leña, bayas, hongos, hiervas medicinales, juego, etc.; los ríos y torrentes, ofrecían agua, peces y posibilidad de transporte; la ciudad procuraba protección al interno de sus murallas y también plazas para el intercambio de productos; la iglesia, construida con el esfuerzo de

\footnotetext{
37 Trascendentes fueron en la construcción de este imaginario los escritos de Aristoteles, San Agustín y Santo Tomás de Aquino. Para reenvíos iniciales cfr. Grossi (2006) p. 74; Costa (2005) pp. 16 ss.

38 Importancia reconocida a la comunidad incluso durante el tardo medioevo. Cfr. PAdOA Schioppa (2007) pp. 115 y ss.

39 Conte (2012) p. 50.

40 Cfr. Conte (2009) pp. 93 y ss. Candian et al. (2002). Para una revista historiográfica de las fuentes medievales relativas a los aprovechamientos colectivos, con especial atención al Derecho español, véase el clásico volumen de NiETo (1964).

41 Lo destaca Grossi (2006) p. 54.
} 
los ciudadanos, confería una pausa espiritual en un lugar limpio y bien decorado ${ }^{42}$. Todas estas observaciones, enseña hoy Mattei, confirman que la dimensión relacional, de estatus, del ser, era, por margen bastante amplio, mucho más relevante que la del tener ${ }^{43}$.

Son, desde luego, innumerables los textos jurídicos que reconocieron eficacia a la rica tradición comunitaria de la época. Pero fue en el ocaso del medioevo cuando un sistema, el anglosajón, supo recoger en modo excepcional la dimensión colectiva y relacional en la utilización de los recursos naturales. No debe olvidarse que paralelamente al primer documento constitucional del Occidente que garantizó, entre otras prerrogativas, el derecho de representación y de propiedad privada de la nobleza frente al rey, la Carta Magna, se redactó la Charter of the Forest, la cual, datada 1217, fue publicada con la primera en 1225 y luego, junto a esta, confirmada en 1297 como the common law of the land mediante la Confirmation of the Charters del rey Eduardo I. Lo que la Charter of the Forest garantizaba en modo paralelo a la Carta Magna fue el acceso y uso a los bienes comunes a todos los súbditos que no poseyeren riqueza ni propiedad privada. La Charter consentía al pueblo, the commoners, el acceso libre a los bosques y el uso de los bienes comunes contenidos en ellos (leña, fruto, hiervas, agua, etc.), prohibiendo su uso exclusivo (incluido el soberano) para el juego y entretenimiento personal ${ }^{44}$. Ahora bien, si apreciamos con cierta altura histórica este pasaje se podrá comprobar que uno de los documentos más importantes de la tradición jurídica occidental posiciona la categoría de los bienes comunes al mismo nivel constitucional que la propiedad privada ${ }^{45}$.

No menos importante para la tradición hispánica fue el reconocimiento de las cosas comunales contenido en las Siete Partidas del rey Don Alfonso el Sabio. El texto, real código de Derecho romano en la versión de los glosadores del siglo XIII, condensó la nutrida tradición ibérico-romana en materia de aprovechamientos colectivos ${ }^{46}$, aunando bajo la expresión de la pertenencia comunal: a) las cosas que comunalmente pertenecen a todas las criaturas del mundo (el aire y las aguas de la lluvia y el mar y su ribera) ${ }^{47}$; b) los ríos, puertos y $\operatorname{caminos}^{48}$; c) las cosas que apartadamente son del común de cada ciudad o villa (esto es, las fuentes, las plazas, los ejidos, los montes y las dehesas y todo lugar semejante que sea establecido y otorgado para provecho comunal de cada ciudad, villa, castillo u otro lugar ${ }^{49}$.

\footnotetext{
42 Cfr. Mattei (2011) p. 27; Linebaugh (2008) pp. 31-36; Grossi (2006) pp. 69-70; Bloch (1968 [1931]) p. 7.

43 Mattei (2011) p. 27.

44 Cfr. Linebaugh (2008) pp. 39, 42.

45 Véase Mattei (2011) p. 33.

46 L. 2, tít. 28, P. 3: "Diferencia hay muy grande entre las cosas de este mundo, pues tales hay de ellas que pertenecen a las aves y a las bestias y a todas las criaturas que viven para poder usar de ellas tanto como los hombres y otras que pertenecen tan solamente a los hombres; y otras hay que pertenecen apartadamente al común de alguna ciudad o villa o castillo o de otro lugar cualquiera donde los hombres moren; y otras hay que pertenecen aun señaladamente a cada hombre para poder ganar o perder el señorío, y otras que no pertenecen a señorío de ningún hombre, ni son contadas en sus bienes".

${ }^{47}$ L. 3, tít. 28, P. 3. Se agrega, además, que la ribera de la mar es de uso comunal de la gente. Así, L. 4, tít. 28 , P. 3.

48 L. 6 , tít. 28 , P. 3.

49 L. 9, tít. 28, P. 3; L. 10, tít. 28, P. 3.
} 
Este sistema fue el mismo que siguió la normativa referida a las Indias españolas, espacio donde las Partidas tuvieron también aplicación supletoria ${ }^{50}$. Una real provisión de 1541 decretó para la provincia del Perú comunes las aguas, los montes y los pastos, permitiendo a cualquier persona llevar allí su ganado. La Recopilación de las Leyes de los Reynos de las Indias de 1680 recogió dicha disposición ordenando: "que los montes y pastos de las tierras contenidos en las mercedes sean también comunes" 51 . Además, fue reconocida en el Derecho indiano la llamada derrota de mieses, esto es, la apertura de las propiedades privadas para permitir el pastoreo común y libre una vez realizada la cosecha de los frutos en los campos. Dijo, el citado texto: "que las tierras sembradas, alzado el pan, sirvan de pasto común"

Pero hay aún otro matiz, muy notorio de la América colonial, que conviene poner de relieve: un universo de formas de titularidad difusa pueden individuarse en la formación de las llamadas reducciones, congregaciones o pueblos de indios, esto es, en la creación de poblados bajo el modelo español de las villas, con el objeto de civilizar y adoctrinar en la fe católica a los grupos indígenas. Existió allí una dimensión colectiva no solo en la creación del ejido -porción de tierra situada en las afueras de las poblaciones rurales donde se apacentaba el ganado en forma comunal ${ }^{53}$, sino que además en el fenómeno jurídico a que dio lugar la amalgama del modelo de poblado español con las formas de organización territorial autóctonas, fenómeno conocido, luego de siglos de hibridación, bajo el rótulo de comunidad indígena ${ }^{54}$.

En fin, los commons en Inglaterra, los communaux en Francia, la Allmende o la Mark en territorios germánicos, los baldíos y las tierras comunales en España, los ejidos y la comunidad indígena en Latinoamérica, reflejan modalidades alternativas a la titularidad individualista de matriz romana y la edificación de categorías de aprovechamiento de los recursos naturales construidas desde abajo, es decir, por sus directos interesados.

La visión de un mundo orgánico, basado en el colectivismo agrario y centrado en la noción del estatus cambiará radicalmente durante la transición del feudalismo al capitalismo. La sociedad eminentemente agraria, que confería a la tierra un valor de uso, se sumergirá en una nueva era donde el suelo será apreciado como bien económico primordial que urgirá mejorar y explotar. De esta forma, de una concepción notablemente política, que entendía la señoría sobre la tierra como una relación de reciprocidad -de derechos y deberes

\footnotetext{
50 Una real cédula de Carlos V de 1530 dispuso la aplicación expresa del Derecho de Castilla conforme al orden establecido por la ley I de Toros, norma que en el último lugar de prelación prescribía recurrir a las leyes de las Siete Partidas. Sobre el punto cfr. GuZmán Brito (2000) pp. 152-153.

51 L. 7, tít., 17, lib. 4.

52 L. 6, tit., 17, lib. 4. Para más antecedentes sobre estas modalidades de uso de la tierra véase MARILUZ URQUIJo (1978) pp. 100 ss. La aplicación de tal disposición, como es de imaginar, no fue simple. En Perú y en Chile su ejecución encontró grandes resistencias por parte de latifundistas y de sostenedores del cerramiento de los fundos. Véase en este tema Góngora (1951) pp. 35 y ss.; Borde y Góngora (1956) pp. 35 y ss.

53 La Real Cédula de 1573 sobre Ordenanzas de descubrimientos, nueva población y pacificación de las Indias de Felipe II ordenó que: "los sitios que han de formar los pueblos y reducciones tengan comodidad de aguas, tierras y montes, entradas y salidas de labranza, y un ejido de una legua de largo, donde los indios puedan apacentar sus ganados, sin que revuelvan con otros de españoles". La edición de estas ordenanzas puede consultarse en Morales Padrón (1979) pp. 489-518.

54 Más antecedentes en Matos Mar (1976) p. 182; Míguez Núñez (2013) pp. 57-58.
} 
mutuos- respecto al grupo de pertenencia, se transitará a una noción que confiere al suelo un mero valor de cambio, entendiendo la titularidad dominical en términos de derechos y relaciones unilaterales ${ }^{55}$.

Importa subrayar que en la construcción de este nuevo imaginario no se asiste a un fenómeno aislado, sino que a una de las tantas consecuencias de los descubrimientos alcanzados en ámbitos de la física, astronomía y matemáticas por los padres de la revolución científica del siglo XVI. En las obras de Newton, Galilei, Descartes, Bacon, y Copérnico la palabra clave es método y de método se hablará en las ciencias, en la filosofía y, por cierto, en el Derecho. El mundo físico fue concebido como una compleja máquina que podía ser entendida en base al análisis reduccionista y experimental ${ }^{56}$. El dualismo cartesiano, que separó la mente de la materia, puso al ser humano en una posición de superioridad respecto al mundo de las cosas permitiendo que la naturaleza fuese ideada como un elemento más del laboratorio. Desde entonces el objeto de la investigación científica serán las cosas y el fin de todo estudio no será otro que, como lo indicó Descartes en una frase que impulsaría la modernidad, convertirnos en "maestros y poseedores de la naturaleza" 57.

De reduccionismo y método científico también se impregnó la ciencia jurídica, que planteó someter el Derecho a un mecanismo mediante la construcción de un rompecabezas interminable basado en un continuo silogismo que acompañaba y unía desde los principios universales del Derecho natural hasta los derechos y obligaciones más específicos de la cotidianidad $^{58}$. En la teoría de Hobbes, por ejemplo, el cuerpo político se compone de seres atomizados unidos por contrato y gobernados desde arriba por un soberano poderoso. El soberano, encarnación de la unidad externa contratada y dispensador de reglas, opera desde afuera el cuerpo social, al igual que el técnico que trabaja en su máquina. De este modo, la tarea que correspondía al Estado para poner fin al desorden y a la anarquía debía basarse en un sistema racional de normas -que Hobbes llamó leyes naturales, de carácter eterno, similares a las leyes de la física- derivadas de la aplicación de la lógica y del razonamiento deductivo a un conjunto de situaciones, conceptos y experiencias ${ }^{59}$.

En el mismo sentido se concibió la relación entre el Derecho y la naturaleza, que ofrece en la formulación de la propiedad un feliz representante del planteamiento científico en el contexto de las ciencias sociales ${ }^{60}$. Como es sabido, la hipótesis de la propiedad presentada por Locke coloca a personas construyendo con su esfuerzo lo propio, trabajando y mejorando la productividad de la tierra, la cual cobra valor gracias al trabajo humano

\footnotetext{
55 Graham (2011) p. 58.

56 Son oportunas las reflexiones del físico Fritjof Capra, quien resumiendo el trascendental cambio de paradigma iniciado con los descubrimientos de la revolución científica, enseña que "The notion of an organic, living, and spiritual universe was replaced by that of the world as a machine, and the world-machine became the dominant metaphor of the modern era”. CAPRA (1997) p. 19.

57 Cfr. Descartes (1966 [1637]) 6e partie, p. 168; Graham (2011) pp. 29 y 31. Para iniciales profundizaciones sobre esta temática en el campo de la filosofía ambiental cfr. LARRÈRE y LARRÈRE (2009).

58 Y se comprende entonces porque el tema es forzoso al abordar la codificación moderna. Véase GUZMÁN BRITO (2000) pp. 83 y ss.

59 Véase Merchant (1980) pp. 210, 213, 214.

60 Sobre este argumento son orientadoras las recientes reflexiones de LE RoY (2011) pp. 258 y ss.
} 
invertido en ella. De ahí que su fruto, la propiedad individual, sea explicado como una extensión poder absoluto -incluso despótico- del titular sobre las cosas ${ }^{61}$. Pero además, es necesario advertir que la concepción de la propiedad lockeana se funda en una relectura de un decisivo pasaje del libro de Génesis (1:28), pieza clave para toda una tradición jurídica que entiende la relación con la naturaleza como el sometimiento de la tierra y sus productos al señorío exclusivo de su titular ${ }^{62}$.

Como resultado de cuanto antecede la tierra será cada vez más apreciada por su valor de cambio y su consiguiente privatización será parte esencial de la acumulación originaria con la que Marx anunciaría la introducción del individualismo agrario ${ }^{63}$. En este nuevo ideario, el trabajo, la tierra y la moneda constituirán elementos fundamentales de la industria y, como tales, se transformarán en cimientos sólidos del actual sistema de mercado. Precisamente, la gran transformación de la que nos habla hacia mediados del siglo XX Karl Polanyi, envolverá, en su fase inicial, la conquista y destrucción de las tierras colectivas y de los campos abiertos mediante su cerramiento y privatización, o sea, la abolición de los derechos feudales, de las costumbres y de los usos sobre la tierra otrora protegidos por las leyes de los bienes comunes, en beneficio de la libertad de exclusión, cultivo y disposición de las heredades y de sus productos ${ }^{64}$.

Nuestra atención debe centrarse nuevamente en Inglaterra, escenario donde a partir de la segunda mitad del siglo XVII crece la oleada de los cerramientos-enclosures- de las tierras. Los cerramientos ingleses constituyen el arquetipo de privatización de recursos colectivamente utilizados ya que en sus diversas modalidades se evidencia un mecanismo de mutación de la tenencia abierta, comunitaria y libre de un bien al modelo de la pertenencia individual y exclusiva ${ }^{65}$. Pero además las enclosures marcan un hito histórico en la privatización de los bienes comunes, pues sellan un pacto que se proyecta hasta nuestros días: la alianza entre Estado y propiedad privada; entre Estado monopolizador del Derecho y soberanía -en el poder reconocido sobre el bien- entregada al individuo ${ }^{66}$. Estas dos nociones dominantes, Estado y privado, colonizarán enteramente el imaginario de la época moderna, imponiendo la notoria ecuación entre cuyos polos oscilarán diversas teorías: "más mercado y menos Estado, más Estado y menos mercado"67.

${ }^{61}$ No huelga aquí recordar la célebre definición de propiedad que propone Sir William Blackstone hacia fines del siglo XVIII: "sole and despotic dominion which one man claims and exercises over the external things of the world, in total exclusion of the right of any other individual in the universe". BLACKSTONE (1893 [17651766]) p. 2.

${ }^{62}$ Cfr. LoCKE (1924 [1690]) secs. 32, 28, 37, 35, 46, 48. Esta y otras consideraciones teológico-doctrinarias han generado un interesante debate filosófico sobre el rol de la tradición judío-cristiana en la creación del orden antropocéntrico que ha conducido a la actual crisis ambiental. Para un inicial examen véase los esenciales aportes de White (1967) y Sessions (1991).

${ }^{63}$ Cfr. Wood (2002) pp. 95 y ss.

${ }^{64}$ Polanyi (1944) cap. 5 y 6.

65 Para detalles sobre las diversas modalidades de cerramiento cfr. DAUTON (1995) pp. 100-102.

${ }^{66}$ Cfr. Rodotà (1990) p. 105.

67 Mattei (2011) p. 34. 
4. Si se examina con el mismo lente historiográfico la cuestión del cerramiento y privatización de las heredades en la Francia rural del siglo XVII, constataremos que la imposición del individualismo agrario ofrece también ahí matices que encierran la lógica que construimos ${ }^{68}$.

Se recordará que bajo el dominio de la escuela fisiocrática las autoridades francesas vieron en la tierra y en su libre propiedad el medio apropiado para hacerse de un sistema agrícola eficaz, y a gran escala, capaz de movilizar la riqueza de la nación ${ }^{69}$. La fisiocracia -vocablo derivado del griego kràtos = poder y physis $=$ naturaleza - aspiraba a gobernar la tierra -fuente de toda la naturaleza- a través de una serie de mecanismos racionales, fundados en la ley del orden natural y entrelazados con nociones de libre competencia y libertad de comercio exterior. No es por casualidad que un fisiócrata, Vincent de Gournay, acuñara la expresión laissez-faire, laissez passer y que el líder de la corriente, François Quesnay, fuere un convencido del racionalismo cartesiano. Así las cosas, las bases librecambistas se encontraban bien cimentadas al momento la Revolución Francesa y se comprende entonces cómo las leyes agrarias que prepararon el terreno para la sistematización propietaria del Código Civil reflejan la anunciada ofensiva programática contra toda forma agraria diversa al individualismo posesivo ${ }^{70}$. En el cúlmine de este proceso, que conduciría al notorio reduccionismo jurídico Estado/individuo, existe una completa sustitución del paradigma del ser y del cuadro relacional construido alrededor de las cosas. Como indica Paolo Grossi "el elogio al propietario que se lee en el Código Civil condensa el reflejo de una entera sociedad que se construye sobre el tener y que señala a sus componentes en el tener individual un aporte insustituible de la plenitud de la propia existencia"71. Y en esta visión, insiste hoy el autor, "la sociedad se reducía a una plataforma inerte, donde el ciudadano, en su atomística individualidad, desaparecía en la masa al igual que la hormiga en el hormiguero" encontrando en el tener, o sea en la riqueza, "la única posibilidad de preeminencia"72.

En este mismo periodo y lugar debe además observarse que la introducción del moderno concepto del dominio público, plasmada en el Code domanial (decreto de 22 de noviembre - 1 de diciembre de 1790) y luego reiterada casi sin modificaciones en el Code Civil, terminaría por cancelar la noción de las res communes omnium al establecer la minimalista fórmula: "todas las partes del territorio francés que no sean susceptibles de una propiedad privada, se considerarán como dependencias del dominio público” (art. 538) ${ }^{73}$. No se crea, con todo, en una dualidad público/privado extrema, pues el Code reservó un breve artículo para una tercera categoría de bienes: los biens communaux, esto es, aquellos sobre cuya propiedad o producto los habitantes de uno o varios municipios tengan derechos

\footnotetext{
68 Sirva como elemental obra para comprender el fenómeno BLOCH (1930).

69 Sobre la relación entre la escuela fisiocrática y la concepción moderna de la propiedad es didáctico MADJARIAN (1991) pp. 188-190. Véase también RebufFa (1974).

70 Para más antecedentes sobre el recorrido legislativo destinado a anular el feudalismo agrario en Francia véase VIVIER (1998) pp. 95 ss.

71 Grossi (1977) pp. 7-8.

72 Grossi (2012) pp. 70-71.

73 Se advierte que los arts. 538, 540 y 541 del Código Civil han sido derogados por al art. 7 de la Ordonnance No 2006-460 del 21 abril 2006 relativa al Code général de la propriété des personnes publiques.
} 
adquiridos (art. 542). Se consagra allí la noción de bienes comunes circunscrita a bienes económicos de variada naturaleza que no forman parte de la propiedad individual de las personas físicas, jurídicas o entes públicos, sino de la propiedad colectiva de una comunidad o vecindad de habitantes, o bien, de cosas que son objeto de situaciones dominicales imperfectas, meros usos, o derechos reales imputables a las mismas comunidades. La conexión con la categoría romana de las res universitatis y con los derechos medievales conferidos a las asociaciones y poblados resulta evidente y su vínculo con otra tipología de bien, por nosotros ya conocida, atempera aún más la inicial bipolaridad público/privado cuando un aislado art. 714, haciendo cuentas con la historia, reconoce la existencia "de cosas que no pertenecen a nadie y cuyo uso es común para todos".

Pero lo que no hizo explícitamente el Código Civil francés fue hecho por sus primeros comentaristas. Así, en las obras de Toullier, Delvincourt y Duranton la categoría de los bienes comunes es contenida en el concepto de dominio público por tratarse, como tal, de cosas situadas fuera del comercio, sujetas a la soberanía de los estados ${ }^{74}$. Contraria, sin embargo, parece ser la opinión del padre de la primera teoría del dominio público, Proudhon, para quien estas cosas (el aire, la luz, los cursos de agua y la mar) no forman parte del concepto "ya que por su inmensidad se sitúan por encina de todo poder del hombre"75. Escapa a nuestro objeto discurrir sobre la colocación de lo común al interno de esta naciente teoría de la demanialidad; lo que interesa en cambio es destacar que bajo el alero de la codificación francesa la categoría de los bienes comunes se pierde pues fuera de la domaine de souveraineté, la doctrina y la jurisprudencia no dialogará más que en términos de domaine public y domaine prive ${ }^{76}$.

La summa divisio del Código Civil francés fue seguida por el derogado Código Civil portugués de 1867, que clasificó las cosas en públicas, comunes y privadas (art. 379),

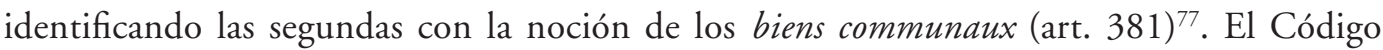
español, a su vez, comprendió el imaginario de los bienes según el enunciado biforme: "Los bienes son de dominio público o de propiedad privada" (art. 338). Y no huelga a esta altura agregar que el trasplante del Code en este y otros estados que siguieron el modelo francés mermaron el citado art. 714 .

Con una técnica diversa y más precisa, nuestro Código Civil desarrolla la materia bajo el título de los bienes nacionales (arts. 589 y ss.), que diferencia de las cosas incapaces de ser apropiadas (arts. 585, 1105). No hay referencia específica a los bienes privados (que implícitamente son dejados a la reglamentación de la propiedad privada), pero despunta, en contraste,

74 Pelloux (1932) pp. 103-109; Wegting (1950) pp. 184-186.

75 En sostén Proudhon ofrece elemental un contraste: las cosas comunes, afirmó, son absolutamente inalienables ya que el orden de la naturaleza del que derivan es inmutable, mientras que la inalienabilidad del dominio público no es absoluta porque ella proviene del orden civil que puede ser siempre modificado PROUDHON (1833) pp. 278-279. Véase también interpretación concordante de PelLoux (1932) pp. 121-122.

76 Proudhon (1833) p. 63. Nótese, además, que la teoría postcodificatoria del dominio público se edificará como una abstracción más, pues, como se ha afirmado, no hay bienes públicos naturales o por derecho natural, sino que su existencia dependerá siempre de un acto del legislador. Véase MARIEnhoff (1960) p. 43.

77 Para detalles sobre el interesante alcance histórico-etnográfico de la voz coisas comuns en el Derecho portugués, véase BrouWER (1999). 
el original reconocimiento de las cosas comunes contenido en el art. 585, categoría que la doctrina civilista encasilla dentro de las cosas inapropiables y por ello no comerciables ${ }^{78}$.

Reza la disposición:

"Las cosas que la naturaleza ha hecho comunes a todos los hombres, como la alta mar, no son susceptibles de dominio, y ninguna nación, corporación o individuo tiene derecho de apropiárselas.

Su uso y goce son determinados entre individuos de una nación por las leyes de esta, y entre distintas naciones por el derecho internacional"

Se notará, además, que la norma desborda hoy los límites del Derecho privado, pues desde 1980 la Constitución Política, conservando la expresión original del Código, estatuye la inapropiabilidad de las cosas que la naturaleza ha hecho comunes a todos los hombres como una de las dos excepciones a la libertad para adquirir el dominio del art. 19 No $23^{79}$.

Diversas razones explican la introducción del art. 585 en nuestro Código Civil. Ante todo, Bello, romanista, no pudo ceder a la omisión de una categoría de res propia de la tradición del Derecho romano clásico, más cuando entre las diversas fuentes que pudo tener a vista destaca la de Luisiana, cuyo Digeste des lois civiles de 1808 y posterior Código de 1825 acogieron las res communes omnium ${ }^{80}$. Asimismo, la influencia, ya advertida por el autor en el Mensaje del Código, de la lumbrera de las Siete Partidas constituye un elemento que no puede ser ajeno al observador. Las Partidas, bien se sabe, representan una versión moderna del Derecho romano y en ellas se deposita, como hemos constatado, un relevante reconocimiento de las cosas comunes. Cuando se lee el art. 585 debe en fin notarse la maestría de Bello en temas de Derecho internacional y que en la materia fue un abierto sostenedor

\footnotetext{
${ }^{78}$ Como se sabe, el Código Civil acoge la distinción entre cosas comerciables y no comerciables (arts. 1461, 2498) y también entre aquellas apropiables y no apropiables (arts. 585 y 1105). Al interior de las cosas incomerciables se comprenden las no comerciables por su destino, que son los bienes nacionales a los que se refiere el 589 y las cosas incomerciables por su naturaleza, consagradas en el art. 585. Cfr. Claro Solar (1992) pp. 162-163; Alessandri Rodríguez y Somarriva Undurraga (1974) pp. 91 y ss.; Peñailillo Arévalo (2007) pp. 61 y ss.

79 Sobre la impronta de la norma en sede ius publicista cfr. Montt Oyarzún (2002) p. 210.

${ }^{80}$ Afirmó el art. III, del cap. I, tít I, Libro II del Digeste: "les choses communes sont celles dont la propriété n'appartient à personne, et dont tous les hommes peuvent se servir librement, conformément à l'usage pour lequel la nature les a destinées; telles sont l'air, l'eau courante, la mer et ses rivages". A su vez, el Código de 1825 declaró en su art. 474 : "Parmi les choses qui ne sont pas susceptibles de propriété, il y en a qui ne peuvent jamais en être l'objet, telles que les choses communes dont les hommes ont la jouissance et le usage". Conviene también destacar que el Código Civil de Puerto Rico reconoce las categorías de cosas susceptibles y no susceptibles de apropiación (art. 273), comprendiendo entre las últimas "aquellas que no pueden ser propiedad particular por razón de su objeto, tales como las cosas en común o sean aquellas cuyo uso y disfrute pertenece a todos los hombres" (art. 474). Influyeron en esta ordenación los arts. 481 y 482 del Código de Luisiana en su versión revisada de 1870. Cfr. Yiannopoulos (1992) p. 15; Yiannopoulos (1961) p. 699. La redacción originaria de 1870 permanece hoy, luego de la revisión del título I, del libro II del año 1978, en los siguientes términos. Art. 448: "Things are divided into common, public, and private; corporeals and incorporeals; and movables and immovables". Art. 449: "Common things may not be owned by anyone. They are such as the air and the high seas that may be freely used by everyone conformably with the use for which nature has intended them". Se advierte, finalmente, que entre los Códigos civiles que copiaron el modelo chileno la codificación ecuatoriana mantiene hoy, en su art. 602, el correlativo del art. 585 del Código chileno.
} 
de la libertad de los mares proclamada en la célebre obra de Hugo Grotius Mare liberum (1609); de ahí el ejemplo introducido en el inciso primero de la disposición ${ }^{81}$.

En lo que respecta a su contenido, la norma dispone, como ocurrió en las fuentes romanas, la inapropiabilidad de las cosas que la naturaleza ha hecho comunes a todos los hombres y a la vista de lo que antecede puede ahora entenderse por qué la doctrina ius privatista, reconociendo implícitamente en ella un valor más histórico que práctico, ha imputado su radio de aplicación al elenco constituido por el aire atmosférico, la alta mar y la luz solar ${ }^{82}$.

Todavía creemos que el universo del art. 585 admite oscilaciones entre criterios que trascienden un estrecho catálogo. Desde luego, puede afirmarse que el concepto íntegro del medio ambiente es condensable en la letra del artículo, pues lo que en otras palabras evidencia la disposición es que la naturaleza, o sea, los bienes de la entera comunidad de los hombres, no pueden ser objeto de apropiación ${ }^{83}$. Lo anterior se explica en función al rol a que son llamados los bienes comunes en todo orden y tiempo, esto es, consentir la subsistencia humana, ya que, como lo destacó Claro Solar, dichas cosas "constituyen una necesidad de la vida misma" ${ }^{84}$.

Atendiendo esta misma lógica, es posible ampliar el elenco a otros ejemplos no necesariamente en correspondencia a recursos naturales. El mismo Bello abordando en sus Principios de Derecho internacional la temática de los bienes de las naciones se refiere implícitamente a una tipología diversa de cosas que caen en el calificativo de comunes: "Es verdad que mientras es libre la navegación de los mares, un descubrimiento en las artes de construcción, en la náutica o en la geografía, no aprovecha exclusivamente a la nación constructora, pero ella reporta las primeras ventajas; y después que ha sido suficientemente premiada, es cuando el invento útil entra en el patrimonio común de los pueblos. Este es el curso ordinario de las cosas, y, sin disputa, el que produce mayor suma de utilidad el género humano; por consiguiente, el más justo" $\$ 5$.

Puede asimismo observarse que no es lejana al ambiente intelectual de Bello la analogía que planteamos: la biblioteca Marcial Martínez de la Facultad de Derecho de la Universidad de Chile, custodia un ejemplar del Código Civil del célebre jurista José Gabriel Ocampo (1798-1882). Al margen del art. 585 Ocampo nos ha dejado de su puño y letra una nota que confirma la extensión potencial de la norma. Se lee, además de una referencia a las Partidas y a las Instituciones de Justiniano, L. de 24 de Julio 1834 Tomo 6 ${ }^{\circ}$, Boletín de las Leyes. El reenvío es a la ley sobre propiedad literaria cuyos arts. 2 y 14 explicitan el reconocimiento de la "propiedad común". Así, si el Fisco fuere el heredero del autor de una obra literaria, esta pasará a ser de propiedad común (art. 2) y transcurridos los términos previstos para disponer exclusivamente de la obra por su autor, heredero o póstumo pro-

\footnotetext{
81 Véase Bello (1864) pp. 36 y ss.

82 Cfr. obras citadas en nota 78 .

83 Fue ese el concepto, si bien en estado embrionario, que se adscribió en el imaginario romano a la categoría de las res communes omniun. Sugiere esta afirmación la actual reconstrucción historiográfica de las fuentes romanas de Maddalena (2011) p. 2618.

84 Claro Solar (1992) p. 163.

85 Bello (1864) pp. 38-39.
} 
pietario "toda obra quedará en el concepto de propiedad común, y todos tendrán expedita acción de negociar con ella como les pareciere" (art. 14) ${ }^{86}$.

Los pasajes de Bello y Ocampo son hoy atribuibles a la expresión "patrimonio cultural común” (art. 11 Ley N 17.336). Así, al expirar el plazo de protección del derecho de autor, las creaciones literarias, artísticas y científicas pueden ser utilizadas por cualquiera, por lo que resulta lógico concluir que una vez entregadas al disfrute público se trata de cosas que la invención humana ha hecho comunes a todos los hombres ${ }^{87}$.

Todavía, regresando al estricto tenor literal del art. 585, no podemos ahora pasar por alto una constatación ya adelantada y que el constitucionalista Arturo Fermandois Vöhringer no olvida cuando sostiene que: "a medida que el mundo se desarrolla y la tecnología avanza los ejemplos de bienes comunes a todos los hombres son cada vez más escasos" y así la excepción a la apropiabilidad del Código Civil "tiene decreciente validez para efectos constitucionales modernos" ${ }^{88}$. Símil conclusión, pero a raíz de otra no menos razonable consideración, se lee en la obra de Santiago Montt Oyarzún para quien la excepción a la apropiabilidad contenida en al art. 19 No 23 de la CP "no reviste ninguna importancia en la construcción de la teoría del dominio público en Chile, pues se refiere a bienes que no son de titularidad estatal" ${ }^{89}$. Justamente, subrayamos, si no estatales, ni privados, el ordenamiento chileno acoge, con nitidez, la dimensión inapropiable de lo común.

Resulta útil fijar, en base a los lineamientos historiográficos que sumariamente se han expuesto, que el diálogo sobre los bienes comunes en la codificación civil ofrece dos modalidades: el Código de Chile y la codificación de Luisiana se refieren a ellos a propósito de las cosas inapropiables por ser comunes a todos los hombres, reenviando a la tradición romanista. En el Derecho francés y en los códigos que le siguieron la categoría atañe a un derecho adquirido por los habitantes de un lugar, y conexo, más bien, con modalidades ancestrales de uso y tenencia local desarrolladas con intensidad durante el medioevo.

5. No es de adscribir a la reflexión jurídica el impulso decisivo al actual debate sobre los bienes comunes. Fue el trabajo conjunto de economistas y ecologistas, reunidos a partir de mediados de los años ochenta en el Panel on the Study of Common Property Resource Management, el principal motor para una contemplación renovada sobre el gobierno de los recursos comunes (common-pool resources). Los estudios desarrollados bajo dicha iniciativa han desafiado la teoría económica convencional -originada en los escritos de Demsetz ${ }^{90}$ y Hardin $^{91}$ - que propone, frente a la opción bipolar público-privado, a la propiedad individual como el instrumento de mayor eficiencia para garantizar el manejo sustentable de los

\footnotetext{
86 Documento disponible bajo el número de pedido: R346.83002632 B446PC1855.

87 Puede, asimismo, apreciarse una notable extensión del patrimonio cultural común en el creciente espacio alcanzado por iniciativas electrónicas como creative commons, fair use, digital commons y el portal SciELO. Para iniciales antecedentes sobre dicho fenómeno cfr. volumen monográfico de la revista Law and Contemporary Problems (2003); Boyle (2008). Véase, además, en intrínseca relación con lo aquí apuntado nota 99.

${ }^{88}$ Fermandois (2010) pp. 237-238.

89 Montt Oyarzún (2002) p. 210.

90 Demsetz (1967).

91 Hardin (1968).
} 
recursos naturales. El nuevo enfoque, hoy institucionalizado en el trabajo de la International Association for the Study of the Commons y respaldado por Nobel de economía conferido en el año 2009 a quien fuere uno de sus principales promotores, la economista Elinor Ostrom (1922-2012), ofrece una tercera opción a la administración de los recursos comunes. No es ya el modelo de propiedad estatal o privada el instrumento garante de la eficiencia, buen uso y acceso democrático a los bienes comunes, sino su autogestión bajo variadas fórmulas (formales e informales) de colectivismo. En esta hipótesis, los usuarios directos son considerados autónomamente capaces de elaborar acuerdos e instituciones idóneas para evitar el monopolio y extinción de los recursos comunes. Lo que se reivindica es entonces la cooperación, la participación directa de la comunidad -bajo un modelo que denominan common property- como herramienta eficaz para garantizar el acceso y uso equitativo y sustentable de los recursos que permiten la subsistencia misma del grupo ${ }^{92}$.

Ciertamente, no puede obviarse la confluencia de este planteamiento con los estudios jurídicos -historiográficos y antropológicos- que han incluido la discusión sobre el colectivismo propietario en el imaginario de las denominadas otras formas de poseer, posicionándolas para la actualidad como modelos alternativos al individualismo propietario ${ }^{93}$. Se observa, bien en la escuela de Ostrom como en los aportes de tinte jurídico, que el centro de la atención no es la búsqueda de una fórmula que abrace la gestión diversa al modelo de la propiedad individual o estatal, sino que la exaltación de un paradigma que niega la relación exclusiva, excluyente y directa $-y$ de ahí esencialmente mercantilista- que une al titular y la cosa para ir al encuentro de formas de utilización de los recursos basadas en la concurrencia asociada de los componentes del grupo interesado. Hay, por ende, un reconocimiento al eminente valor social del uso de ciertos bienes; social en términos del poder conferido a los sujetos en la participación de las decisiones relativas a bienes primordiales para la existencia y el perfeccionamiento de la persona ${ }^{94}$.

En esta dimensión, la moderna reflexión jurídica sobre los bienes comunes propone una lógica no centrada sobre el sujeto ni sobre la cosa; el acento hoy se sitúa en la función que el bien desempeña en la sociedad, premisa que consiente definir comunes los bienes funcionales al ejercicio de derechos fundamentales y al libre desarrollo de la personalidad. Se trata, en las palabras de Rodotà, de una reflexión relacionada a los bienes primarios, necesarios para garantizar el goce de los derechos fundamentales e individuar los intereses colectivos, así como las modalidades de uso y de gestión de los mismos bienes ${ }^{95}$. Sobre esta base, Alberto Lucarelli, teórico publicista empeñado en la causa activa de los bienes comu-

92 Entre los primeros trabajos dedicados a la gestión de recursos naturales sobre la base de instrumentos alternativos a la propiedad privada y estatal, véase, por todos, VV.AA. (1986); MCCAY y ACHeSON (1987); BERKES (1989); y, por cierto, el elemental volumen de Ostrom (1990).

93 El reenvío forzoso en esta temática es a un libro que ha hecho escuela no solo en Europa: Grossi (1977). Asimismo, por su influencia en la literatura jurídica hispánica del siglo XX no pueden omitirse los trabajos de Costa (1898) y de NieTo (1964). Entre nosotros se consultará el excepcional volumen de LipSCHUTZ (1956). Los reenvíos bibliográficos abundan en obras contemporáneas referidas a Latinoamérica, véase, por todos, DEmélas y Vivier (2003); Herzog (2007); Míguez NúÑez (2013) pp. 172-173, nota 161.

94 Sobre este carácter limitativo a la lógica de la apropiabilidad ya advertía RoDOTÃ (1990) p. 27.

95 Rodotà (2012b) p. 107. 
nes, los define como res communes omnium caracterizadas por poseer una destinación al fin de la utilidad general y al cumplimiento de la cohesión económico-social y territorial ${ }^{96}$. Ello, empero, no confiere al bien una existencia condicionada al uso que le den las personas; por el contrario, el bien cobra importancia por su función y su función es pensada en consideración a los recursos que algunas cosas puedan generar. De esta forma, la existencia de los bienes comunes se justifica en la hipótesis de que algunos recursos pueden ser mejor aprovechados mediante un uso colectivo ${ }^{97}$. De ahí que toda la construcción moderna en la materia principia en el reconocimiento de la aptitud colectiva de los frutos y productos de ciertas cosas. Se trata, por consiguiente, de una lógica que une la satisfacción de los derechos fundamentales con una palabra clave, y diremos antagónica, a la propiedad: el acceso.

El confronte propiedad/acceso no ofrece novedad alguna; es posible acceder a un bien, y gozar de su utilidad, sin asumir la calidad de propietario. Sin embargo, si se aprecia con mayor detención esta afirmación podrá observarse que el mismo concepto de dominio muta, pues la propiedad no deber ser confinada, como lo ha hecho la teoría liberal, al solo derecho de excluir a terceros respecto al uso o al goce de determinados bienes, sino que puede igualmente consistir en un derecho individual a no ser excluido, por el actuar de otros, en dicho uso y goce ${ }^{98}$. Así, se transita de la lógica exclusiva a la inclusiva; de la exclusión a la accesión. Este, a nuestro modo de ver, es el raciocinio a partir del cual se debe leer el art. 585 del CC: las cosas comunes a todos los hombres proponen el pasaje de la exclusividad a un modelo participatorio respecto al acceso, uso y gestión de los bienes.

Como se podrá apreciar, son muchas las dimensiones de los bienes comunes e, indudablemente, ellas no se agotan en la alusión directa a los derechos fundamentales de los habitantes de una nación. Una lectura más general de los intereses protegidos conduce a una reflexión que traspasa los límites de la soberanía nacional ya que considera en su radio de acción toda la cuestión relativa a la salvaguardia del ecosistema local y universal. Bello, reconociendo la factura supraestatal de la materia, consignó la reglamentación de su uso y goce entre distintas naciones al Derecho internacional (art. 582 inc. 2o). El tiempo ha dado contenido a la norma y así una trascendental reflexión jurídica se ha originado en el ámbito internacional a partir de la introducción de la expresión "patrimonio común de la humanidad” realizada, entre otros instrumentos más o menos explícitos, por la Declaración de la Conferencia de las Naciones Unidas sobre el Medio Ambiente Humano (Estocolmo, 1972 ${ }^{99}$. Asimismo, quien se adentre hoy en dichas áreas constatará que el interés en torno

\footnotetext{
96 LuCARelli (2007) p. 91. Conviene sin embargo advertir que no es pasiva la doctrina respecto a la utilización de la categoría romana de las res communes omniun en la actual teorización de los bienes comunes. Véase FioRENTINI (2010).

97 Véase Gambaro (2012) p. 338.

98 Es la reflexión de C. B. Machperson, que destaca hoy Rodotà (2012b) pp. 108-109.

99 El término patrimonio común de la humanidad fue introducido en 1954 por la Convención de La Haya para la Protección de los Bienes Culturales en caso de Conflicto y establecido como norma vinculante en el Derecho internacional en el Tratado sobre los principios que deben regir las actividades de los Estados en la exploración y utilización del espacio ultraterrestre, incluso la Luna y otros cuerpos celestes (1967). Entre los diversos instrumentos de Derecho internacional, referencias explícitas al término se encuentran en el Acuerdo que debe regir las actividades de los Estados en la Luna y otros cuerpos celestes (1979) y en la Convención de las Naciones Unidas sobre el Derecho del Mar (1982). Sobre la relevancia del patrominio común de la humanidad como paliativo a las formas
} 
al cambio climático, los océanos, la atmósfera, la Antártica y el espacio exterior, cobra cada vez más importancia en la literatura filosófico-ambiental, económica y político-jurídica bajo el significativo título de los global commons ${ }^{100}$. Se comprende que en esta lectura la humanidad se erige como sujeto de los derechos y deberes fundamentales, precisándose la adopción de una filosofía solidaria entre los estados, atendida la responsabilidad común que incumbe en la salvaguardia de los bienes esenciales del ecosistema ${ }^{101}$.

Es por lo dicho que entre las más recientes experiencias que proponen una reelaboración de las categorías de bienes debemos insistir en el proyecto italiano de reforma al Código Civil presentado por la Comisión sobre Bienes Públicos presidida por Stefano Rodotà. El proyecto, consignado al Ministerio de la Justicia en febrero de 2008, ha abierto un intenso debate sobre la necesidad de adecuar la taxonomía de los bienes públicos a los requerimientos socionormativos actuales ${ }^{102}$. La Comisión propone una summa divisio ya familiar a nosotros: los bienes son comunes, públicos o privados, y se confiere a los primeros un contenido que engloba los razonamientos aquí vertidos ${ }^{103}$.

oligárquicas de apropiación de los recursos naturales por los estados es relevante Dupuy (1985) pp. 66-67. Entre nosotros Cea Egaña, comentando el art. 585 del CC, ha afirmado que "En términos aplicables a fenómenos de nuestro tiempo, pensamos que el concepto comentado abarca el denominado patrimonio de la humanidad, como el genoma humano". CEA EGAÑA (2004) p. 517. Nótese, en efecto, que la Ley N²0.120 sobre investigación científica en el ser humano, su genoma y prohíbe la clonación humana de 22/09/2006 ha estatuido en su art. 8 inc. $1^{\circ}$ que "El conocimiento del genoma humano es patrimonio común de la humanidad. En consecuencia, nadie puede atribuirse ni constituir propiedad sobre el mismo ni sobre parte de él”.

100 Cfr. Vogler (1995); Goldman (1998); Buck (1998); Nonini (2007); Harrison y McIntosh SundSTROM (2010); Axelrod et al. (2010). En la producción hispana cfr. Gordillo (2006). Debe también notarse que la dimensión global de los bienes comunes no se detiene en la estricta esfera de la protección del ambiente. Es también fundamental identificar bienes inmateriales como el conocimiento y las tradiciones, los bienes culturales o el patrimonio intelectual de un pueblo, pues en ellos subyace la cultura local a partir de la cual es posible gobernar el fenómeno del cambio global. Véase RоротÀ (2012b) p. 122.

101 Ayuda a comprender este paradigma una lectura universalista y funcional de los bienes comunes. Universal, pues el sujeto titular del derecho de acceso y goce de tales bienes no es otro que la humanidad; y funcional, porque no se atiende a la naturaleza del bien ni a la relación de titularidad dominical sino que a su vínculo dirigido a consentir la realización de derechos fundamentales del hombre. De esta forma, las instituciones públicas administran los bienes comunes en calidad de tutores de los intereses generales pero no como propietarios, por lo que también allí puede observarse, desde un punto de vista funcional, una dimensión publicista en el gobierno de tales bienes. Véase LuCARELLi (2007) pp. 95-96.

102 Las voces en la doctrina italiana se multiplican. Véase últimamente Gambaro (2012) pp. 59 y ss. Y ello sobre todo a partir del debate generado por una relevante recepción de la voz bienes comunes en sede jurisdiccional. Me refiero a la sentencia de las Secciones Unidas de la Corte de Casación de 14 de febrero 2011, No 3665 sobre la cual véase, por todos, Cascione (2011); Lieto (2011); Cortese (2011); Ciafardini (2011); Carapezza Figlia (2012b).

103 Comunes, son aquellas cosas que representan utilidad directamente funcional al efectivo ejercicio de derechos fundamentales. Dichos bienes deben ser salvaguardados por el ordenamiento jurídico también con respecto a las generaciones futuras. Titulares de estos pueden ser personas públicas o privadas. Se señalan como bienes comunes, entre otros: los ríos, torrentes, lagos y otras aguas, el aire, los parques, los bosques, áreas boscosas, las zonas de montaña de alta cuota, los glaciares y los hielos perennes, las zonas de costa declaradas reserva ambiental, la fauna salvaje y la flora protegida, los bienes arqueológicos, culturales, ambientales y las demás zonas paisajísticas tuteladas. Los titulares de los bienes comunes pueden ser personas públicas o privadas. En el caso de titularidad pública los bienes comunes serán administrados por sujetos públicos y quedan situados fuera del comercio. En casos excepcionales, previstos por la ley, podrán darse en concesión a tiempo limitado pero resguardando el criterio de solidaridad de las utilidades comunes producidas por dichos bienes. El goce colectivo 
6. Los bienes comunes naturales (el agua, el aire puro, el ambiente, el mar), los bienes comunes sociales (el saber, la memoria histórica, los bienes culturales), los bienes comunes materiales (las plazas, los jardines públicos), los bienes comunes inmateriales (el espacio común de la web) deben ser objeto de una profunda reflexión crítica. La plaza no es urbanísticamente bien común (diremos, será un bien nacional de uso público) pero lo es en cuanto espacio de encuentro, de acceso social, de intercambio existencial. Pues bien, la lectura moderna de los bienes comunes conduce a una comprensión de los bienes públicos como funcionales al perseguimiento y satisfacción del interés de la colectividad. La naturaleza de estos no deriva, por ende, de la pertenencia a una categoría específica de bienes (privados o públicos) sino del beneficio que ellos generan para la misma colectividad.

Entre nosotros ha sido Alejandro Vergara Blanco quien con mucho acierto ha propuesto un similar miramiento en el cambio de eje del debate respecto a los bienes nacionales de uso público. La discusión, sostiene el autor, "se encuentra mal enfocada pues está algo entrampada en una cuestión que quizás no es esencial: en el empeño por defender una propiedad estatal, o de todos los ciudadanos, o de todos nosotros de estos bienes; esto es, se ha introducido el tema en una lógica patrimonialista, de repartición de titularidades de estos bienes, propia del derecho civil, pues de acuerdo a este criterio tan generalizado, los bienes tienen que ser de alguien, o de todos o del estado. Esta es una disputa algo inútil, pues más que propugnar patrimonios estatales o de todos los ciudadanos, la verdad es que pareciera que lo importante para el derecho vigente es que estos bienes estén al alcance de todos. Es el alcance de todos, su finalidad, su destino público, del público, del pueblo, lo que pareciera importar más"104.

La consideración anterior es de primaria importancia puesto que se recaba una lectura eminentemente constitucional de la teoría de los bienes. Así, porque los bienes comunes son instrumentos puestos al servicio de la realización de valores constitucionalmente garantizados, resulta forzoso armonizar el interés colectivo que subyace en los arts. 585 y 589 del Código Civil con el compromiso constitucional de la realización espiritual y material de la persona humana a cuyo servicio se empeña el Estado (art. 1 inc. $4^{\circ} \mathrm{CP}$ ) y a cuya existencia limita la propia soberanía (art. 5 inc. $2^{\circ} \mathrm{CP}$ ). Todavía, es necesario apuntar que la contemplación de la dimensión común de los bienes no se agota allí, pues debe también tener en cuenta la función social de la propiedad (art. 19 No 24 inc. $2^{\circ} \mathrm{CP}$ ), sobre todo si se recuerda que ella comprende cuanto exijan los intereses generales de la Nación, la utilidad y la salubridad pública y la conservación del patrimonio ambiental, es decir, materias concernientes a demandas propias de bienes con aptitud común. El llamado a la función social es un llamado a una propiedad establecida al servicio del bien común, de una propiedad que vive en sociedad y que por lo tanto no puede prescindir de un componente público ${ }^{105}$. Toca,

del bien debe ser en todo caso garantizado. Se concede acción jurisdiccional para hacer efectiva la protección y goce efectivo de los bienes comunes. La acción relativa al daño corresponderá exclusivamente al Estado. Para un análisis detallado del proyecto, véase por todos, Lucarelli (2010); Perlingieri (2009); Reviglio (2008); Renna (2009). Se consultarán además voces de Lucarelli, Dalisa y CeCere en el número monográfico de la Rassegna di diritto pubblico europeo (2007).

104 Vergara Blanco (1999) pp. 82-83.

105 Cfr. Miller (1999) pp. 8 y 10. 
por lo tanto, al Estado garantizar el bienestar económico colectivo a través de la introducción de un régimen de bienes capaz de establecer la equidad en las relaciones sociales ${ }^{106}$. En él descansa el poder de diseñar de instrumentos jurídicos apropiados para garantizar el valor social de los bienes. Lo hará mediante regulación de normas urbanísticas, de salubridad, de preservación cultural y ambiental, que confieren a la propiedad privada aquel límite derivado de la coexistencia social y que revaloriza la dimensión humana de toda persona diversa al titular. Lo hará permitiendo el ensanche del goce a la entera colectividad de las utilidades generadas por bienes que posean una relevancia social ${ }^{107}$. Lo hará, en la arena de la propiedad pública, mediante la adaptación del ordenamiento demanial a los requerimientos actuales; mediante la creación de fórmulas que consientan una mejor utilización económica y un aumento de la productividad de los bienes de su dominio; mediante la declaración de inalienabilidad de ciertos bienes no idóneos a lógicas exclusivamente mercantiles. Lo hará, en definitiva, mediante la salvaguardia intergeneracional de los recursos colectivos al fin de concretizar los derechos inviolables del hombre ${ }^{108}$.

Pero entiéndase bien, lo anterior no implica una vuelta atrás: el análisis crítico de las actuales políticas de privatización que trasluce el debate sobre los bienes comunes no debe enfrascarnos en la clásica disputa política entre el modelo del liberalismo (individualismo) y del estatalismo (comunitarismo). Existen, como indica Mattei, en realidad muchas combinaciones intermedias entre estas dos concepciones que el instrumental jurídico debe saber dominar. La economía de mercado y la economía pública están destinadas a caminar juntas por mucho tiempo aún; se necesitará reformular ambos sectores para asegurar una concepción racional y realista de las relaciones entre Estado y mercado, entre sociedad y economía, que tenga en cuenta los factores políticos, sociales, culturales y ambientales necesarios para lograr la realización de una sociedad basada en la igualdad de condiciones ${ }^{109}$. Una sociedad con más público comporta una sociedad con más bienes comunes, con más recursos posicionados en la esfera de lo común. Prevalece en ella la solidaridad, la justicia social en la distribución de los recursos, permitiendo, en definitiva, que la cualidad de la vida sea colocada en una posición prioritaria respecto a la cantidad económica a que aspira la riqueza material.

\footnotetext{
106 En la construcción de este significado de la función social es crucial RodOTÀ (1960); RoDOTÃ (1968).

107 Es de notar que la construcción teórica de la general accesibilidad y del goce colectivo de los bienes privados reenvía a los principios constitucionales de la igualdad y de la función social de la propiedad. El planteamiento debe además su origen a los trabajos de la doctrina civilística italiana de los años setenta. Sobre el punto véase Carapezza Figlia (2012a) pp. 1076-1078. Entre nosotros Peñailillo Arévalo incorpora la dimensión colectiva como un elemento orientador en la decisión fundamental relativa al ámbito de aplicación de la propiedad privada. Surgen así, como verdaderas constantes y rasgos distintivos del actual derecho de cosas, los principios la equidad en el reparto y de la equidad del aprovechamiento. Peñailillo Arévalo (2007) pp. 84-85.

108 Un notable ejemplo en este sentido es el compromiso estatal asumido por el Estado ecuatoriano en el art. 395 No 1 de la Constitución del 2008: "1. El Estado garantizará un modelo sustentable de desarrollo, ambientalmente equilibrado y respetuoso de la diversidad cultural, que conserve la biodiversidad y la capacidad de regeneración natural de los ecosistemas, y asegure la satisfacción de las necesidades de las generaciones presentes y futuras".

109 Véase Mattei et al. (2007) pp. 10 y 12.
} 


\section{BIBLIOGRAFÍA CITADA}

Alessandri Rodríguez, Arturo y Manuel Somarriva Undurraga (1974): Los bienes y los derechos reales: curso de derecho civil (Santiago, Editorial Nascimento).

Axelrod, Regina S. et al. (2010): The Global Environment: Institutions, Law, and Policy (Washington D. C., CQ Press).

Bello, Andrés (1864): Principios de Derecho internacional (Valparaíso, Imprenta de la Patria, tercera edición).

Benkler, Yochai (1999): "Free As the Air to Common Use: First Amendment Constraints on Enclosure of the Public Domain", New York University Law Review, Vol. 74, No 2: pp. 354-446.

Berkes, Fikret (edit.) (1989): Common Property Resources: Ecology and Community-Based Sustainable Development (London, Belhaven press).

Blackstone, William (1893 [1765-1766]): Commentaries on the Laws of England in Four Books, Vol. I, Book II (Philadelphia, J.B. Lippincott Co.).

Bloch, Marc (1930): "La Lutte pour l'individualisme agraire dans la France du XVIII siècle”, Annales d'histoire économique et sociale, Vol. 2, No 7: pp. 329-383; Vol. 2, No 8: pp. 511-556.

BLOCH, Marc (1968 [1931]): Les caractères originaux de l'histoire rurale française, tomo I (Paris, Librairie Armand Colin).

Bonfante, Pietro (1966): Corso di diritto romano, Vol. II, 1 (Milano, Giuffrè).

Borde, Jean y Góngora, Mario (1956): Evolución de la propiedad rural en el Valle del Puangue, tomo 1 (Santiago, Editorial Universitaria).

Boyle, James (2003a): "The Second Enclosure Movement And The Construction Of The Public Domain", Law and Contemporary Problems, Vol. 66: pp. 33-74.

Boyle, James (2003b): "Foreword: The Opposed of Property?", Law and Contemporary Problems, No 66: pp. 1-32.

Boyle, James (2008): Bound By Law (Duke University Press). Disponible en: <http://web. law.duke.edu/cspd/comics/>.

Brouwer, Ronald (1999): "Changing Name-Tags. A Legal Anthropological Approach to Communal Lands in Portugal”, Journal of Legal Pluralism, No 43: pp. 1-30.

Buck, Susan J. (1998): The Global Commons: An Introduction (London, Earthscan publications).

Burdon, Peter (2013): Earth Jurisprudence, Private Property and the Environment (Abingdon Oxfordshire, Routledge).

Candian, Albina et al. (2002): Property - Propriété - Eigentum (Padova, Cedam).

Capra, Fritjof (1982): The Turning Point: Science, Society, and the Rising Culture (New York, Bantam books).

CaPra, Fritjof (1997): The Web of Life. A New Synthesis of Mind and Matter (London, Flamingo).

Carapezza Figlia, Gabriele (2012a): "Premesse ricostruttive del concetto di beni comuni nella civilistica italiana degli anni Settanta”, Rassegna di diritto civile, No 4: pp. 10611088 . 
Carapezza Figlia, Gabriele (2012b): "Proprietà e funzione sociale. La problematica dei beni comuni nella giurisprudenza delle Sezione unite”, Rassegna di diritto civile, No 2: pp. 535-549.

Cascione, Claudia Morgana (2011): "Le Sezioni unite oltre il codice civile. Per un ripensamento della categoria dei beni pubblici”, Giurisprudenza italiana, No 12: pp. 25062514

Castellón Venegas, Hugo y Rebolledo Contreras, Laura (1999): Aspectos sobre la constitucionalización del derecho civil (Santiago, Editorial Jurídica ConoSur).

Cea Egaña, José Luis (2004): Derecho constitucional chileno. Tomo II (Santiago, Ediciones Universidad Católica de Chile).

Ciafardini, Luciano (2011): "I beni pubblici 'comuni': a proposito delle valli da pesca della laguna di Venezia”, Giustizia civile, No 12: pp. 2844-2847.

Claro Solar, Luis (1992): Explicaciones de derecho civil chileno y comparado, tomo VI (Santiago, Editorial Jurídica de Chile).

Conte, Emanuele (2009): Diritto comune: storia e storiografia di un sistema dinamico (Bologna, Il Mulino).

Conte, Emanuele (2012): "Beni comuni e domini collettivi tra storia e diritto", en MARella, Maria Rosaria (edit.), Oltre il pubblico e il privato. Per un diritto dei beni comuni (Verona, ombre corte) pp. 43-59.

Cordero Quinzacara, Eduardo (2006): “La dogmática constitucional de la propiedad en el derecho chileno", Revista de Derecho (Valdivia), Vol. 19, No 1: pp. 125-148.

Cordero Quinzacara, Eduardo (2008): "De la propiedad a las propiedades. La evolución de la concepción liberal de la propiedad”, Revista de Derecho de la Pontificia Universidad Católica de Valparaíso, No 31: pp. 493-525.

Cortese, Fulvio (2011): "Dalle valli da pesca ai beni comuni: la cassazione rilegge lo statuto dei beni pubblici? (comm. a Corte di cassazione, sez. un., 14 febbraio 2011, No 3665)", Giornale di diritto amministrativo, No 17-11: pp. 1170-1178.

Costa, Joaquín (1898): Colectivismo agrario en España (Madrid, Imprenta de San Francisco de Sales).

Costa, Pietro (2005): Cittadinanza (Roma-Bari, Laterza).

Coyle Sean y Morrow, Karen (2004): The Philosophical Foundations of Environmental Law: Property, Rights, and Nature (Oxford-Portland, Hart).

Dauton, Martin J. (1995): Progress and Poverty: An Economic and Social History of Britain 1700-1850 (Oxford, Oxford University Press).

Davies, Margaret (2007): Property. Meanings, Histories, Theories (Abingdon RoutledgeCavendish).

Demélas, Marie Danielle y VIVIER, Nadine (edits.) (2003): Les propriétés collectives face aux attaques libérales (1750-1914) Europe occidentale et Amérique latine (Rennes, Presses Universitaires de Rennes).

Demsetz, Harold (1967): “Towards a Theory of Property Rights”, American Economic Review, No 57: pp. 347-359.

Descartes (1966 [1637]): Discours de la méthode (Paris, Bibliothèque de la Pléiade, Éd. Gallimard). 
DupuY, René-Jean (1895): "Réflexions sur le patrimoine commun de l'humanité", Droits, No 1: pp. 63-71.

Fermandois VÖHringer, Arturo (2010): Derecho constitucional económico. Regulación, tributos y propiedad, tomo II (Santiago, Ediciones Universidad Católica de Chile).

Fiorentini, Mario (2010): "L'acqua da bene economico e "res communis omnium" a bene colectivo", Analisi giuridica dell'economia, No 1: pp. 39-78.

Gambaro, Antonio (2012): I beni, en Trattato di diritto civile e commerciale Cicu-MessineoMengoni (Milano, Giuffrè).

Goldman, Michael (edit.) (1998): Privatizing Nature: Political Struggles for the Global Commons (London, Pluto Press).

Góngora, Mario (1951): El estado en el derecho Indiano. Época de fundación 1492-1570 (Santiago, Editorial Universitaria).

Gordillo, José Luis (edit.) (2006): La protección de los bienes comunes de la humanidad: Un desafio para la política y el derecho del siglo XXI (Madrid, Trotta).

Graham, Nicole (2011): Lawscape: Property, Environment and Law (Abingdon Oxfordshire, Routledge).

GraY, Kevin (1994): "Equitable Property", Current Legal Problems, No 47, pt. 2: pp. $157-$ 214.

Grossi, Paolo (1977): Un altro modo di possedere. L'emersione di forme alternative di proprietà alla coscienza giuridica postunitaria (Milano, Giuffrè).

Grossi, Paolo (1988): "La proprietà e le proprietà: un ripensamento teorico e il suo significato per lo storico del diritto", Quaderni Fiorentini, No 17: pp. 359-422.

Grossi, Paolo (2006): L'ordine giuridico medievale (Roma-Bari, Laterza).

Grossi, Paolo (2012): Introduzione al Novecento giuridico (Roma-Bari, Laterza).

Grosso, Giuseppe (1941): Corso di diritto romano. Le cose (Torino, Giappichelli).

Gudynas, Eduardo (2009): El Mandato Ecológico. Derechos de la naturaleza y políticas ambientales en la nueva Constitución (Quito, Abya Yala).

GUZMÁn BRITO, Alejandro (1995): Las cosas incorporales en la doctrina y en el derecho positivo (Santiago, Editorial Jurídica de Chile).

GuZMÁn Brito, Alejandro (2000): La codificación civil en Iberoamérica. Siglos XIX y XX (Santiago, Editorial Jurídica de Chile).

Hardin, Garret (1968): “The Tragedy of the Commons", Science, No 162: pp. 1243-1248.

Harrison, Kathryn y McIntosh Sundstrom, Lisa (edits.) (2010): Global Commons, Domestic Decisions: The Comparative Politics of Climate Change (Cambridge, Ma.London The MIT Press).

Hart, Michael y Negri, Antonio (2009): Commonwealth (Cambridge Ma., Belknap Press). Harvey, Davis (2003): The New Imperialism (Oxford, Oxford University Press).

Herzog, Tamar (2007): “Terres et déserts, société et sauvagerie. De la communauté en Amérique et en Castille à l'époque moderne”, Annales HSS, No 62-3: pp. 507-538.

Larrère, Catherine y LaRrère, Raphaël (2009): Du bon usage de la nature: pour une philosophie de la nature (Paris, Flammarion).

Law and Contemporary Problems (2003) No 66. Disponible en: <http://scholarship.law. duke.edu/lcp/vol66/iss $1 />$. 
Le Roy, Étienne (2011): La terre de l'autre. Une anthropologie des régimes d'appropriation foncière (Paris, L.G.D.J).

Lieto, Sara (2011): "Beni comuni, diritti fondamentali e stato sociale. La Corte di Cassazione oltre la prospettiva della proprietà codicistica”, Politica del Diritto, No 42-2: pp. 331-350.

Linebaugh, Peter (2008): The Magna Carta Manifesto. Liberties and Commons for All (Berkeley-Los Angeles-Boston, University of California Press).

LipschuTz, Alejandro (1956): La comunidad indígena en América y en Chile: su pasado histórico y sus perspectivas (Santiago, Editorial Universitaria).

Locke, John (1924 [1690]): Two Treatises of Civil Government, introduction by W. S. Carpenter, Book II, Chap. V(London, Dent; New York, Dutton, Everyman's library).

LuCARELli, Alberto (2007): "Note minime per una teoria giuridica dei beni comuni", Quale Stato, No 3-4: pp. 87-98.

LuCARelli, Alberto (2010): "Proprietà pubblica, principi costituzionali e tutela dei diritti fondamentali. Il progetto di riforma del codice civile: un'occasione perduta?”, en MATTEI, Ugo et al. (edit.), I beni pubblici. Dal governo democratico dell'economia alla riforma del codice civile (Roma, Scienze e Lettere) pp. 85-95.

Macpherson, C. B. (1962): The Political Theory of Possessive Individualism: Hobbes to Locke (Oxford, Clarendon Press).

Maddalena, Paolo (2011): "I beni comuni nel codice civile, nella tradizione romanistica e nella costituzione della repubblica italiana”, Giurisprudenza costituzionale, No 56-3: pp. 2612-2630.

MADJARIAN, Gregorie (1991): L'invention de la propriété (Paris, L'Harmattan).

Marella, Maria Rosaria (2011): "Il diritto dei beni comuni. Un invito alla discussione", Rivista critica del diritto privato, Vol. 29, No 1: pp. 103-118.

Marienhoff, Miguel S. (1960): Tratado del dominio público (Buenos Aires, Tipografía Editora Argentina).

Mariluz Urquijo, José María (1978): El régimen de la tierra en el derecho indiano (Buenos Aires, Editorial Perrot).

Matos Mar, José (1976): “Comunidades indígenas en el área andina”, en Matos Mar, José (edit.), Hacienda, comunidad y campesinado en el Perú (Lima, Iep) pp. 179-217.

MatteI, Ugo et al. (2007): Invertire la rotta. Idee per una riforma della proprietà pubblica (Bologna, Il Mulino).

Mattei, Ugo et al. (2010): I beni pubblici. Dal governo democratico dell'economia alla riforma del codice civile (Roma, Scienze e Lettere).

Mattei, Ugo (2011): Beni comuni. Un Manifesto (Roma-Bari, Laterza).

McCay, Bonnie J. y Acheson James M. (edits.) (1987): The Question of the Commons. The Culture and Ecology of Communal Resources (Tucson, Az., University of Arizona Press).

Merchant, Carolyn (1980): The Death of Nature. Women, Ecology and the Scientific Revolution (New York, HarperCollins).

Míguez NúNEEZ, Rodrigo (2010): "Pour une déconstruction du concept de propriété dans les Andes centrales", Revue Internationale de Droit Comparé, No 4: pp. 981-1006. 
Míguez Núñez, Rodrigo (2013): Terra di Scontri: alterazioni e rivendicazioni del diritto alla terra nelle Ande centrali (Milano, Giuffrè).

Miller, David (1999): Principles of Social Justice (Cambridge Ma., Harvard University Press).

Montt Oyarzún, Santiago (2002): El dominio público. Estudio de su régimen especial de protección y utilización (Santiago, ConoSur).

Morales Padrón, Francisco (1979): Teoría y leyes de la conquista (Madrid, Ed. Cultura Hispánica).

Nieto, Alejandro (1964): Bienes comunales (Madrid, Editorial Revista de Derecho Privado).

Nonini, Donald M. (edit.) (2007): The Global Idea of the Commons (New York-Oxford, Berghahn books).

Ostrom, Elinor (1990): Governing the commons: the evolution of institutions for collective action (Cambridge, Cambridge University press).

Padoa Schioppa, Antonio (2007): Storia del diritto in Europa. Dal medioevo all'età contemporanea (Bologna, Il Mulino).

Pelloux, Robert (1932): Le problème du domaine public. Evolution et solutions actuelles (Paris, Dalloz).

Peñailillo Arévalo, Daniel (2007): Los bienes, la propiedad y otros derechos reales (Santiago, Editorial Jurídica de Chile).

Perlingieri, Pietro (2009): "Normazione per principi: riflessioni intorno alla proposta della Commissione sui beni pubblici", Rassegna di diritto civile, No 4: pp. 1184-1190.

PolanyI, Karl (1944): The Great Transformation (New York, Holt, Rinehart \& Winston Inc.).

Proudhon, Jean Baptiste Victor (1833): Traité du domaine public, ou de la distinction des biens considérés principalement par rapport au domaine public, tomo 1 (Dijon, Victor Lagier Libraire-Éditeur).

Pugliatti, Salvatore (1952): "La proprietà e le proprietà (con riguardo particolare alla proprietà terriera)", Atti del terzo congresso nazionale di diritto agrario - Palermo, 1923 ottobre 1952, en Pugliatti, Salvatore (1954): La proprietà nel nuovo diritto (Milano, Giuffrè) pp. 145 ss.

Pugliatt, Salvatore (1959): "Beni (teoria generale)", Enciclopedia del diritto, Vol. V: pp. 164-189.

RAmis, Álvaro (2012): "Hacia la revolución de los bienes comunes", en: La defensa de los bienes comunes. Recuperar los recursos naturales, selección de artículos de Le Monde Diplomatique (Santiago, Editorial Aún Creemos en los Sueños) pp. 11-16.

Rassegna di diritTo pubblico europeo (2007), No 2 (número monográfico).

Rebuffa, Giorgio (1974): Origine della ricchezza e diritto di proprieta: Quesnay e Turgot (Milano, Giuffrè).

Reich, Charles A. (1964): "The New Property", The Yale Law Journal, Vol. 73, No 5: pp. 733-787.

Reich, Charles A. (1990): “The New Property After 25 Years”, University of San Francisco Law Review, No 24, pp. 223-271.

Rèmond-Goullloud, Martine (1989): Du droit de détroire (Paris, PUF). 
Renna, Mauro (2009): "Le prospettive di reforma delle norme del codice civile sui beni pubblici", Il diritto dell'economia, No 1: pp. 11-26.

Reviglio, Edoardo (2008): "Per una riforma del regime giuridico dei beni pubblici. Le proposte della Commissione Rodotà", Politica del diritto, No 3: pp. 531-550.

Rodotà, Stefano (1960): "Note critiche in tema di proprietà", Rivista trimestrale di diritto e procedura civile, No 14: pp. 1252-1341.

RoDotÀ, Stefano (1968): "Proprietà (diritto vigente)", Novissimo digesto italiano, Vol. XIV: pp. 125-146.

Rodotà, Stefano (1990): Il terribile diritto. Studi sulla proprietà privata (Milano, Il Mulino, segunda edición).

RodotÀ, Stefano (2007): "Linee guida per un nuovo codice dei beni pubblici”, en MatTeI, Ugo et al., Invertire la rotta. Idee per una riforma della proprietà pubblica (Bologna, Il Mulino) pp. 357-365.

RodotÀ, Stefano (2011a): "Beni comuni e categorie giuridiche: una rivisitazione necessaria”, Questione giustizia, No 5: pp. 237-247.

Rodotà, Stefano (2011b): "Editoriale", Rivista critica del diritto privato, Vol. 29, No 1: pp. 3-8.

Rodotà, Stefano (2012a): "Beni comuni: una strategia globale contro lo human divide", en Marella, Maria Rosaria (edit.), Oltre il pubblico e il privato. Per un diritto dei beni comuni (Verona, ombre corte) pp. 9-28.

RodotÀ, Stefano (2012b): Il diritto di avere diritti (Roma-Bari, Laterza).

Schiavone, Aldo (2005): Ius. L'invenzione del diritto in Occidente (Torino, Einaudi).

Schmitz Vaccaro, Christian (2009): "Propiedad intelectual, dominio público y equilibrio de intereses", Revista Chilena de Derecho, Vol. 36, N²: pp. 343-367.

Sessions, George (1991): "Ecocentrism and the Anthropocentrism Detour", ReVISION No 13-3: pp. 109-115.

SHIVA, Vandana (1997): Biopiracy: The Plunder of Nature and Knowledge (Cambridge Ma., South End Press).

SteInberg, Theodore (1995): Slide Mountain: Or, the Folly of Owning Nature (Berkeley Ca., University of California Press).

Treggiari, Ferdinando (2012): "Bene comune: la città medievale", en Marella, Maria Rosaria (edit.), Oltre il pubblico e il privato. Per un diritto dei beni comuni (Verona, ombre corte) pp. 222-229.

Vergara Blanco, Alejandro (1992): "La propietarización de los derechos", Revista de Derecho de la Universidad Católica de Valparaíso, Vol. 14: pp. 281-291.

Vergara Blanco, Alejandro (1997): "Tres problemas actuales sobre bienes del dominio público: caminos privados de uso público; acceso a playas de mar y a orillas de ríos y lagos; y subsuelo de bienes públicos", Revista de Derecho, Vol. 18: pp. 423-434.

Vergara Blanco, Alejandro (1999): "Naturaleza jurídica de los «bienes nacionales de uso público»", Ius Publicum, No 3: pp. 73-83.

Vergara Blanco, Alejandro (2001): "La summa divisio de bienes y recursos naturales en la Constitución de 1980", en: 20 años de la Constitución Chilena, 1981-2001 (Santiago, ConoSur, Universidad Finis Terrae) pp. 369-389. 
Míguez NúnEEZ, Rodrigo — "De las cosas comunes a todos los hombres notas para un debate"

Vergara Blanco, Alejandro (2002): "Las aguas como bien público (no estatal) y lo privado en el derecho chileno: evolución legislativa y su proyecto de reforma", Revista de Derecho Administrativo Económico, No 1: pp. 575-589.

VIVIER, Nadine (1998): Propriété collective et identité communale. Les biens communaux en France 1750-1914 (Paris, Publications de la Sorbonne).

VocI, Pasquale (1998): Manuale di diritto romano. Parte generale, Vol. II (Giuffrè, Milano).

Vogler, John (1995): The Global Commons: A Regime Analysis (Chichester, John Wiley \& Sons).

VV.AA (1986): Proceedings of the Conference on Common Property Resource Management: April 21-26, 1985, Annapolis, Maryland (Washington, D.C., National Academy of Sciences).

Wegting, Wilhelmus Gerardus (1950): Domaine public et res extra commercium. Étude historique du droit romain français et néerlandais (Pays-Bas, N. Samson n.v.; Paris, Recueil Sirey).

White, Lynn (1967): "The historical roots of our ecologic crisis", Science, No 155: pp. 1203-1027.

Wood, Ellen Meiksins (2002): The Origin of Capitalism. A Longer View (London-New York, Verso).

Yiannopoulos, Athanassios N. (1961): "Common, Public, and Private Things in Louisiana: Civilian Tradition and Modern Practice”, Louisiana Law Review, Vol. 21, No 4: pp. 697-748.

Yiannopoulos, Athanassios N. (1992): "Two Critical Years in the Life of the Louisiana Civil Code: 1870 and 1913”, Louisiana Law Review, Vol. 53, No 1: pp. 5-33.

Zaffaroni, Eugenio Raúl (2012): La Pachamama y el humano (Buenos Aires, Ediciones Madres de la Plaza de Mayo).

ZicCardi, Giovanni (2013): Resistance, Liberation Technology and Human Rights in the Digital Age (Dordrecht, Springer).

Zoz, Maria Gabriella (1999): Riflessioni in tema di res publicae (Torino, Giappichelli).

Zúñiga Urbina, Francisco (2005): "Constitución y Dominio Público (Dominio Público de Minas y Aguas Terrestres)”, Revista Ius et Praxis, Vol. 11, No 2: pp. 65-101. 